\title{
Tailoring Terpesomes and Leciplex for the Effective Ocular Conveyance of Moxifloxacin Hydrochloride (Comparative Assessment): In-vitro, Ex-vivo, and In-vivo Evaluation
}

\author{
Rofida Albash' \\ Menna M Abdellatif ${ }^{2}$ \\ Mariam Hassan (iD ${ }^{3}$ \\ Noha M Badawi ${ }^{4}$ \\ 'Department of Pharmaceutics, College \\ of Pharmaceutical Sciences and Drug \\ Manufacturing, Misr University for \\ Science and Technology, Giza, Egypt; \\ ${ }^{2}$ Department of Industrial Pharmacy, \\ College of Pharmaceutical Sciences and \\ Drug Manufacturing, Misr University for \\ Science and Technology, Giza, Egypt; \\ ${ }^{3}$ Department of Microbiology and \\ Immunology, Faculty of Pharmacy, Cairo \\ University, Cairo, II562, Egypt; \\ ${ }^{4}$ Department of Pharmaceutics and \\ Pharmaceutical Technology, Faculty of \\ Pharmacy, The British University in Egypt, \\ Cairo, Egypt
}

\begin{abstract}
Aim: To compare the ability of both terpesomes (TPs) and leciplex (LPs) loaded moxifloxacin hydrochloride (MOX) for enhancing ocular drug conveyance.

Methods: Two separate $2^{1} .3^{1}$ full-factorial trials were established to determine the influence of multiple variables upon nanovesicles properties and select the optimized formulae using Design Expert ${ }^{\mathbb{B}}$ software. The thin-film hydration method was used to formulate TPs, while the single-step procedure was used for LPs. All formulae were characterized for their entrapment efficiency percent (EE\%), particle size distribution (PS), polydispersity index (PDI), and zeta potential (ZP). Then, the optimized formulae were selected, evaluated, and compared for additional assessments.

Results: The optimized formulae TP4 and LP1 showed EE\% of $84.14 \pm 0.21$ and 78.47 $\pm 0.17 \%$, PS of $578.65 \pm 5.65$ and $102.41 \pm 3.39 \mathrm{~nm}$, PDI of $0.56 \pm 0.04$ and $0.28 \pm 0.01$, ZP of $-12.50 \pm 0.30$ and $32.50 \pm 0.50 \mathrm{mV}$, respectively. Further, LP1 showed enhanced corneal permeation across cow cornea compared to MOX solution and TP4. Besides, confocal laser scanning microscopy assessment viewed valuable infiltration from the fluoro-labeled LP through corneal layers compared to TP. LP1 showed spherical morphology and, its ability to adhere to mucus membranes was justified. Further, LP1 showed superiority over MOX solution in biofilm inhibition and eradication in addition to the treatment of infected mice with methicillinresistant Staphylococcus aureus without any inflammatory response. Finally, the histopathological study verified the harmlessness and biocompatibility of the assembled LPs.

Conclusion: The gained outcomes confirmed the capability of utilizing LPs as a successful nanovesicle for the ocular conveyance of MOX over TPs and MOX solution.
\end{abstract}

Keywords: biofilm, confocal laser microscope, moxifloxacin hydrochloride, MRSA, leciplex, ocular drug conveyance, terpesomes

\section{Introduction}

Several severe complications such as corneal damage, vision loss, or even complete blindness may occur in case of inadequate treatment of bacterial keratitis. Corneal infections are complications of extended wearing of contact lenses, sutures, and glaucoma tubes. According to microbiologists, pathogens can build biofilms on eye surfaces, leading to difficult bacterial eradication due to biofilm drug resistance. ${ }^{1}$

Staphylococcus aureus corneal infections represent a threat to visual acuity. One of the critical challenges in treating Staphylococcal corneal infections is the
Correspondence: Mariam Hassan Department of Microbiology and Immunology, Faculty of Pharmacy, Cairo University, Kasr El-Aini Street, Cairo,

I I562, Egypt

Tel +20(122)3376326

Email mariam.hassan@pharma.cu.edu.eg 
emergence of antibiotic resistance, in addition, most of the pathogenic strains are multi-drug resistant. Methicillinresistant Staphylococcus aureus (MRSA) is considered a community and hospital-gained virulent pathogen associated with increasing persistent and complicated eye infections. Therefore, there is a demanding urge for the development of alternative therapeutic systems with improved antimicrobial activity. ${ }^{2}$

Moxifloxacin Hydrochloride (MOX) is an antimicrobial of low toxicity and has an effect against gram (+ve), and gram (-ve) bacteria. ${ }^{3}$ MOX is either given as an intracameral injection or topically. However, the intracameral injection may cause corneal endothelial toxicity and toxic anterior segment syndrome. On the other hand, topical administration of MOX solutions suffers from low ocular bioavailability $(1-7 \%)$ due to the short residence time, superior lacrimal drainage, and inferior infiltration through the corneal barriers. The human cornea is composed of three distinct layers lipophilic epithelium, hydrophilic stroma, and endothelium. Endothelial cells are the major components of the ocular blood barriers found in the uvea, and these cells prevent the delivery of hydrophilic drugs through the aqueous humor. For that reason, drugs that have a high $\log \mathrm{P}$ value (2-4) can permeate through the cornea easily. Therefore, a promising approach with high residence time and permeation via cornea is desired to conquer the short washout time and enhance the inadequate drug permeation through the cornea. ${ }^{4}$

MOX is characterized by high aqueous solubility so its delivery through nanocarriers is a good choice. Accordingly, encapsulation of MOX into lipid-based nanocarrier would provide sustained release which led to a reduction in the effective therapeutic dose and dosedependent shortcomings of the drug. ${ }^{5}$

Terpesomes (TPs) are terpenes containing vesicles, previously described by Albash et al, to treat ocular candidiasis. ${ }^{6}$ Terpenes are naturally occurring substances derived from essential oils and made up of several isoprene units. $^{6}$ Terpenes are not only well-known penetration enhancers, but they also possess both antimicrobial and antifungal activities as a consequence of their residence in the lipophilic entities of the cell bilayer; which allows constituents of essential oils to be delivered to the inner of the cell, leading to cytoplasmic infiltration, and cell death. ${ }^{7}$

On the other hand, Leciplex is a new vesicular nanosystem based on the combination of negatively charged phospholipids, cationic surfactants, and Transcutol ${ }^{\circledR 8}{ }^{8}$ Leciplex (LPs) were previously reported by Hassan et al for the treatment of glaucoma and concluded that LPs improve the ocular bioavailability and transcorneal permeability of Carvedilol. $^{8}$ The privilege of LPs over conventional systems is their ability to be fabricated via a single-procedure fabrication that provides nanosized vesicular systems via simple blending. ${ }^{8,9}$

Based on the effective utilization of both TPs (negatively charged vesicles) and LPs (positively charged vesicles) as successful ocular drug delivery systems, the present study suggests that both carriers could successfully deliver MOX. Therefore, two separate $2^{1} \cdot 3^{1}$ full factorial designs utilizing the Design Expert ${ }^{\circledR}$ program were employed to investigate the impact of different variables on TPs and LPs and compare their influence. Phospholipid (PC) concentration $\left(\mathrm{X}_{1}\right)$ and terpene type $\left(\mathrm{X}_{2}\right)$ were selected as independent factors for TPs design while surfactant (SAA) type $\left(\mathrm{X}_{1}\right)$ and PC: (SAA) molar ratio $\left(\mathrm{X}_{2}\right)$ were selected as independent factors for LPs design. On the other hand, entrapment efficiency percent $\left(\mathrm{EE} \%\right.$; $\left.\mathrm{Y}_{1}\right)$, particle size $\left(\mathrm{PS} ; \mathrm{Y}_{2}\right)$, polydispersity index $\left(\mathrm{PDI} ; \mathrm{Y}_{3}\right)$, and zeta potential $\left(\mathrm{ZP} ; \mathrm{Y}_{4}\right)$ were chosen as dependent responses. The best-achieved formulae were subjected to further ex-vivo permeation study and confocal laser scanning microscopy examination. After that, the nanovesicles that achieved the highest permeation and illustrated the highest fluorescence intensity were subjected to additional in-vitro and in-vivo antibacterial assessments.

\section{Materials}

Moxifloxacin hydrochloride (MOX) was donated from Kahira Pharmaceutical Co. (Cairo, Egypt). L- $\alpha$ phosphatidylcholine from egg yolk, cetyltrimethylammonium bromide (CTAB), dimethyldidodecylammonium bromide (DDAB), fluorescein diacetate (FDA), and mucin from porcine stomach type II were purchased from SigmaAldrich Chemical Co. (St. Louis, MO, USA). Fenchone, cineole, and limonene were purchased from Alfa Aesar (GmbH, Germany). Diethylene glycol monoethyl ether (Transcutol $^{\circledR}$ HP) was obtained from Gattefosse (Cedex, France). Acetonitrile and methanol (HPLC) were purchased from Merck (Darmstadt, Germany).

\section{Methods}

\section{Preparation of MOX-Loaded TPs}

TPs were prepared by varying both terpenes type and PC (soy phosphatidylcholine) concentration using the thinfilm hydration method (Table 1). At first, PC and terpenes were solubilized into $10 \mathrm{~mL}$ methanol in a round flask. By 
Table I Full Factorial Design for the Optimization of MOXLoaded TPs and LPs

\begin{tabular}{|c|c|c|c|}
\hline Factors (Independent & \multicolumn{3}{|c|}{ Levels } \\
\hline$X_{1}: P C$ concentration & $1 \%$ & \multicolumn{2}{|c|}{$3 \%$} \\
\hline $\mathrm{X}_{2}:$ Terpene type & Fenchone & Cineole & Limonene \\
\hline $\begin{array}{l}\text { Factors (Independent Variables) } \\
\text { for LPs Design }\end{array}$ & \multicolumn{3}{|c|}{ Levels } \\
\hline $\mathrm{X}_{1}$ : SAA type & CTAB & \multicolumn{2}{|c|}{ DDAB } \\
\hline $\mathrm{X}_{2}$ : PC: SAA molar ratio & I:I & $\mathrm{I}: 2$ & $\mathrm{I}: 5$ \\
\hline $\begin{array}{l}\text { Responses (Dependent } \\
\text { Variables) }\end{array}$ & \multicolumn{3}{|c|}{ Constraints } \\
\hline$Y_{1}:$ EE (\%) & \multicolumn{3}{|c|}{ Maximize } \\
\hline$Y_{2}: P S(n m)$ & \multicolumn{3}{|c|}{ Minimize } \\
\hline $\mathrm{Y}_{3}: \mathrm{PDI}$ & \multicolumn{3}{|c|}{ Minimize } \\
\hline $\mathrm{Y}_{4}: \mathrm{ZP}(\mathrm{mV})$ & \multicolumn{3}{|c|}{ Maximize } \\
\hline
\end{tabular}

Abbreviations: $E E \%$, entrapment efficiency percent; $C T A B$, cetrimonium bromide; $\mathrm{DDAB}$, didodecyldimethylammonium bromide; MOX, moxifloxacin hydrochloride; PS, particle size; PDI, polydispersity index; PC, phospholipid; ZP, zeta potential; LPs, leciplex; TPs, terpesomes.

maintaining pressure under vacuum for $30 \mathrm{~min}$, methanol was evaporated at $60^{\circ} \mathrm{C}$ using a rotatory evaporator (Rotavapor, Heidolph VV 2000, Burladingen, Germany) at $90 \mathrm{rpm}$ to form a thin film of TPs. The formed film was hydrated with $10 \mathrm{~mL}$ water containing $50 \mathrm{mg} \mathrm{MOX}$ at $60{ }^{\circ} \mathrm{C}$. For more efficient film hydration, glass beads were used during the hydration step for $45 \mathrm{~min}^{10}$

\section{Preparation of MOX-Loaded LPs}

A simple single-step procedure was used in preparing LPs by varying both PC: SAA molar ratio and type of cationic SAA (Table 1). At first, PC and cationic SAA were dissolved in Transcutol ${ }^{\circledR} \mathrm{HP}(0.5 \mathrm{~mL})$ and heated at $70^{\circ} \mathrm{C}$ in a water-bath after that $50 \mathrm{mg}$ of MOX dissolved in $9.5 \mathrm{~mL}$ water and kept at $70^{\circ} \mathrm{C}$ was added with continuous mixing till homogeneous nano-dispersion was obtained. ${ }^{8,11,12}$

\section{Characterization and Optimization of MOX-Loaded TPs and LPs \\ Determination of EE\%}

EE\% of both TPs and LPs was calculated via the dialysis method for separating the non-entrapped MOX from the nanovesicles. ${ }^{13} 1 \mathrm{~mL}$ of the MOX-loaded nanovesicles was placed in a dialysis bag (M.W of 12,000 Dalton) and then immersed in $100 \mathrm{~mL}$ of distilled water magnetically stirred at $60 \mathrm{rpm} .{ }^{14}$ At selected time-points, aliquots were removed, and MOX was spectrophotometrically assayed at $288 \mathrm{~nm}$ employing a UV-Vis spectrophotometer (UV-1650; Shimadzu Corp., Kyoto, Japan) until a constant concentration was obtained. EE $\%$ was then calculated by the following equation:

$$
\mathrm{EE}(\%)=\frac{\text { Total MOX amount }- \text { Diffused MOX }}{\text { Total MOX amount }} \times 100
$$

Each evaluation is the average of three individual experiment \pm SD.

\section{Determination of PS, PDI, and ZP}

PS, PDI, and ZP of the fabricated formulations were assessed through the light scattering approach at $25^{\circ} \mathrm{C}$ via Malvern Zetasizer (Malvern Instruments Ltd., Malvern, UK). The assessments were fulfilled after appropriate dilution. ${ }^{10,11}$ All evaluations were assessed in three trials $\pm \mathrm{SD}$.

\section{Optimization of MOX Loaded TPs and LPs Formulations Using Full Factorial Designs}

A $2^{1} .3^{1}$ factorial experiment was used to investigate the influence of multiple factors in fabricating TPs and LPs in two separate designs via Design Expert ${ }^{\circledR}$ software version 11 (Stat Ease, Inc., Minneapolis, MN, USA). In the first experimental design, two factors were inspected for TPs formulation: one factor with two levels $\left(\mathrm{X}_{1}\right.$ : $\mathrm{PC}$ concentration) and another factor with three levels $\left(\mathrm{X}_{2}\right.$ : terpene type). While in the other design, for LPs formulation, the two evaluated factors were $\left(\mathrm{X}_{1}\right.$ : cationic SAA type $)$ at two levels and $\left(\mathrm{X}_{2}\right.$ : PC: SAA molar ratio) at three levels. The EE\% $\left(\mathrm{Y}_{1}\right)$, PS $\left(\mathrm{Y}_{2}\right)$, PDI $\left(\mathrm{Y}_{3}\right)$, and $\mathrm{ZP}\left(\mathrm{Y}_{4}\right)$ were used as dependent variables in both designs (Table 1).

\section{Selecting the Optimized MOX-TPs and MOX-LPs Formulae}

The selection of optimized formulae relied on the desirability tool, which allowed the analysis of each response simultaneously. The principle for choosing the optimized formulae was producing the least PS and PDI and the highest $\mathrm{EE} \%$ and $\mathrm{ZP}{ }^{15}$

\section{Ex-vivo Studies \\ Ex-vivo Permeation Studies}

A corneal permeation study was performed through a Franz diffusion cell with a surface area of $0.785 \mathrm{~cm}^{2}$. 
Precisely, $1 \mathrm{~mL}$ of MOX solution, the optimized TP, and optimized LP, equal to $5 \mathrm{mg}$ of MOX, were transferred in the donor cells. The receptor chamber was loaded with $12 \mathrm{~mL}$ of phosphate buffer saline $\left(\mathrm{pH} \mathrm{7.4)}\right.$ at $37{ }^{\circ} \mathrm{C}$. At a definite time, $0.5 \mathrm{~mL}$ of receiver media was removed, and an exact volume of fresh media was added into the receiver chamber. The samples were analyzed by using HPLC, where a $\mathrm{C}_{18}$ column was used with a mobile phase of $($ water + triethylamine $(2 \%, \mathrm{v} / \mathrm{v}))$ : acetonitrile $=$ 90:10 (v/v\%); the $\mathrm{pH}$ of water phase being adjusted with phosphoric acid to 6.0. The flow rate of the mobile phase was $1.5 \mathrm{~mL} / \mathrm{min}$, and UV detection at $290 \mathrm{~nm}$ was employed. The column was adjusted at $45{ }^{\circ} \mathrm{C}$. Method validation parameters indicate linear dynamic range $0.2-$ $2.0 \mu \mathrm{g} / \mathrm{mL}$ with LOQ ca. $0.20 \mu \mathrm{g} / \mathrm{mL}$ and LOD ca. 0.05 $\mu \mathrm{g} / \mathrm{mL}$ for all analytes. ${ }^{16}$ The permeation flux $\left(J_{\max }\right)$ at 6 $h$ and the enhancement ratio (ER) were calculated. The experiment was performed in three trials \pm SD. Statistical significance was inspected via one-way ANOVA by SPSS $^{\circledR}$ software 22.0. The post-hoc test was performed utilizing Tukey's honest significant difference (HSD) test.

\section{Confocal Laser Scanning Microscopy Study (CLSM)}

To trace the permeation of the optimized TP and LP formulae through different corneal layers, the formulae were prepared as previously described, except that the drug was replaced with FDA at $1 \%(\mathrm{w} / \mathrm{v}) .{ }^{17}$ Cow cornea was mounted in diffusion chambers with the previous aspects of the ex-vivo permeation study. To mimic the administration of optimized formulae in contact with the eye surface, FDA-loaded nanovesicles were applied on the corneal surface and remained for $6 \mathrm{~h}$. Longitudinal sections kept in paraffin wax and cut into sections using a microtome (Rotary Leica RM2245; Leica Biosystems, Wetzlar, Germany) were observed for fluorescence in the corneal tissues. The slides were visualized employing an inverted microscope (LSM 710; Carl Zeiss, Oberkochen, Germany). The excitation and emission wavelengths of the FDA were $\lambda_{\max } 497 \mathrm{~nm}$ and $\lambda_{\max } 516 \mathrm{~nm}$, respectively. The cornea was optically scanned under a $40 \times$ objective lens (EC-Plan Neofluar 63x/01.40 Oil DICM27). Confocal images were supplied by LSM Image Browser software, release 4.2 (Carl Zeiss Microimaging $\mathrm{GmbH}$, Jena, Germany). ${ }^{18}$ For comparative assessment between the optimized TP and the optimized LP, several sections were selected in corneal tissues and, the intensity of light was compared and analyzed. Statistical significance was assessed by Student's $t$-test employing SPSS ${ }^{\circledR}$ software
22.0. Difference at $\mathrm{P} \geq 0.05$ was regarded as significant. The experiment was performed in three trials \pm SD.

\section{Morphology}

Based on ex-vivo studies the morphology was assessed for the selected formula via a transmission electron microscope (TEM) (JEM-1230, Joel, Tokyo, Japan). The diluted formula was placed on the top of a carbon-coated grid and negatively stained with a $1 \%$ phosphotungstic acid, then dried for visualization. ${ }^{19}$

\section{Stability Study}

The physical stability of the selected formula was investigated to monitor the extent of vesicles' growth, drug leakage, or any other physical change. The selected formula was kept at room temperature for three months and then assessed by comparing the EE\%, PS, PDI and, ZP of the stored formula with the fresh vesicles. Besides, the system was visually observed for any sedimentation. ${ }^{20}$

\section{$\mathrm{pH}$ Measurement}

To test the selected formula's ocular tolerance, the $\mathrm{pH}$ was measured using a calibrated potentiometer (Inolab pH 720, WTW, Germany) at ambient temperature. The results were the mean of triplicate trials $\pm \mathrm{SD} .{ }^{21}$

\section{Evaluation of Mucoadhesion Properties of Nanovesicles}

The mucoadhesive properties of the selected formula were evaluated where $1 \% \mathrm{w} / \mathrm{v}$ of porcine mucin was mixed with the same quantity of the selected formula in a dropwise manner under stirring. The stirring was conducted for an additional five minutes, and the mixture was allowed to equilibrate overnight at room temperature. The surface charge of mucin particles and the charge of mucoadhesive nanovesicles in the presence of mucin were evaluated by zetasizer. $^{22}$

\section{Determination of Minimum Inhibitory Concentration (MIC)}

The antibacterial potency of the selected formula and MOX solution was assessed against MRSA USA300. Accordingly, MIC of both was assessed by the broth microdilution approach in agreement with the guidelines of the Clinical and Laboratory Standards Institute. $150 \mu \mathrm{L}$ of double efficacy Mueller Hinton broth was pipetted into each well of a sterile 96-well microplate, and $150 \mu \mathrm{L}$ of 
the selected formula/solution $(5 \mu \mathrm{g} / \mathrm{mL})$ was after that dropped into the first well of each column. ${ }^{23,24}$ Subsequent two-fold dilutions were performed across the microplates $(2.5-0.0195 \mu \mathrm{g} / \mathrm{mL})$. Bacterial inoculum (MRSA USA300) was then added to the wells, and each well was inoculated with $15 \mu \mathrm{L}$ of bacterial suspension $\left(10^{8} \mathrm{CFU} / \mathrm{mL}\right)$. One column was utilized as a sterility control (neither bacterial suspension nor selected formula was added). In addition, another column was employed as a growth control (inoculated with bacterial suspension without adding the test formula). The microplates were incubated under aerobic conditions at $37^{\circ} \mathrm{C}$ for $24 \mathrm{~h}$, and then the MIC was recorded. The MIC was known as the lowest concentration with no detectable bacterial growth (no turbidity). The experiment was repeated in three trials \pm SD.

\section{Effect of the Selected Formula on the Anti-Biofilm Activity of MOX}

The anti-biofilm activity of the selected formula was compared to that of the MOX solution.

\section{Biofilm Inhibition Assay}

The selected formula and MOX solution were tested at concentrations below the $\mathrm{MIC}(\mathrm{MIC} / 2, \mathrm{MIC} / 4, \mathrm{MIC} / 8$, $\mathrm{MIC} / 16, \mathrm{MIC} / 32, \mathrm{MIC} / 64, \mathrm{MIC} / 128$, and $\mathrm{MIC} / 256)$. The biofilm inhibition assessment was done as mentioned before. $^{25}$ Precisely, the MRSA USA300 suspension $\left(10^{8}\right.$ $\mathrm{CFU} / \mathrm{mL}$ ) in tryptic soy broth (TSB) was added in a flatbottom 96-well ELISA plate $(200 \mu \mathrm{L} /$ well $)$. Different concentrations of the selected formula/solution were added to the loaded wells ( $20 \mu \mathrm{L} /$ well). Nothing was added to the control wells (untreated, 100\% reference measurements). The plates were then incubated at $37^{\circ} \mathrm{C}$ for $24 \mathrm{~h}$ at static aerobic conditions. After incubation, the grown cultures' optical density (OD600) was assessed by a spectrophotometric plate reader (Biotek, Synergy 2, USA). The formed biofilms were quantified as follows; wells were washed with saline then dried. The dried biofilm was then stained with crystal violet $(0.1 \% \mathrm{w} / \mathrm{v}, 200$ $\mu \mathrm{L} /$ well) for 30 minutes at room temperature. The wells were then washed three times with distilled water and dried. The crystal violet in the stained biofilm was liquified by adding absolute ethanol $(200 \mu \mathrm{L} /$ well) and incubating for 20 minutes at $4{ }^{\circ} \mathrm{C}$ (to minimize evaporation). The $\mathrm{OD}_{550}$ of the crystal violet solutions was assessed by spectrophotometric plate reader and divided by $\mathrm{OD}_{600}$ of the grown cultures for normalization. The biofilm inhibition $\%$ was calculated by the following equation: ${ }^{25}$

$$
\text { Biofilm inhibition } \%=\frac{\text { OD Control }- \text { OD Test }}{\text { OD Control }} \times 100
$$

\section{Biofilm Eradication Assay}

The ability of the selected formula and MOX solution to eradicate the previously established MRSA USA300 biofilm was investigated. The selected formula and MOX solution were tested at concentrations below the $\mathrm{MIC}(\mathrm{MIC} / 2, \mathrm{MIC} / 4$, $\mathrm{MIC} / 8, \mathrm{MIC} / 16, \mathrm{MIC} / 32, \mathrm{MIC} / 64, \mathrm{MIC} / 128$, and MIC/256). The experiment was performed as described before. ${ }^{25} \mathrm{MRSA}$ USA300 suspension in TSB broth $\left(10^{6} \mathrm{CFU} / \mathrm{mL}\right)$ was loaded in a flat-bottom 96-well enzyme-linked immune sorbent assay (ELISA) plate $\left(200 \mu \mathrm{L} /\right.$ well) and incubated at $37^{\circ} \mathrm{C}$ for $24 \mathrm{~h}$ in static aerobic status. After incubation, $\mathrm{OD}_{600}$ of the grown cultures was assessed by an automated spectrophotometric plate reader (Biotek, Synergy 2, USA). The wells were carefully evacuated by aspiration. Several concentrations of the selected formula/solution were prepared in fresh TSB broth and were added to the biofilm plate $(200 \mu \mathrm{L} /$ well). Nothing was added to the biofilm control wells (untreated biofilm, 100\% reference value). The plate was then re-incubated at $37^{\circ} \mathrm{C}$ for $24 \mathrm{~h}$. After the treatment period, crystal violet staining and measurement were performed as described previously. The experiment was repeated three independent times. The biofilm eradication $\%$ was calculated by the following equation: ${ }^{25}$

$$
\text { Biofilm eradication } \%=\frac{\text { OD Control }- \text { OD Test }}{\text { OD Control }} \times 100
$$

\section{In-vivo Assessment of the Selected Formula Murine MRSA Corneal Infection Model and Histopathologic Evaluation}

All the animal care and experiments in this assessment were authorized via the Research Ethics Committee of the Faculty of Pharmacy, Cairo University (Approval no. MI 2796), adhering to the "Guide for the Care and Use of Laboratory Animals" declared via the Institute of Laboratory Animal Research (Washington, DC, USA). The murine model of MRSA corneal infection was conducted as described before with slight modifications. ${ }^{26}$ Twenty-eight male BALB/C mice (7 weeks old weighing 
150-200 gm) were gained from the Modern Veterinary Office for Laboratory Animals, Cairo, Egypt. Standard commercial food and tap water ad libitum were provided to the mice, and they were permitted to habituate for seven days $\left(25 \pm 2{ }^{\circ} \mathrm{C}, 12: 12 \mathrm{~h}\right.$ light-dark) before establishing the experiment. All the eyes were first inspected with a slit lamp. Only animals without any signs of ocular inflammation were included in the study. The mice were anesthetized with ketamine (70 $\mathrm{mg} / \mathrm{kg}$ i.p.), and $0.5 \%$ proparacaine was applied to the eyes of each mouse. A 30gauge needle was used to inoculate each eye with only one colony of MRSA USA300; 3-4 scratches were made through the cornea taking care not to infiltrate the superficial stroma. The scratches were then inoculated with a 5 $\mu \mathrm{L}$ of MRSA USA300 suspension $\left(7 \times 10^{8} \mathrm{CFU}\right)$ employing a micropipette; after that, the eyelids were closed manually for 15 seconds. Then, mice were divided into two groups (fourteen mice per group, $n=14$ ) after infection. One group was treated with the selected formula, while the other was treated with the MOX solution. Treatments were administered in $5 \mu \mathrm{L}$ aliquots to the right eye (of each mouse) twice per day, beginning 24 $\mathrm{h}$ post-infection and ending $72 \mathrm{~h}$ post-infection. The left eye of each mouse did not receive treatment and acted as the negative control. At the end of the experiment, the animals were euthanized, and the whole eyes were dissected. Eight mice from each group $(\mathrm{n}=8)$ were employed to assess the number of viable Staphylococcus aureus colonies. Each eye was homogenized in $0.5 \mathrm{~mL}$ saline (homogenizer, DAIHAN-scientific-pacific lab). The homogenates were diluted ten folds and plated for the viable aerobic count on mannitol salt agar (MSA), then incubated at $37{ }^{\circ} \mathrm{C}$ for $24 \mathrm{~h}$. The colony-forming units (CFU) were counted, and the results of treated groups (right eyes) were correlated to each other and to that of the untreated negative controls (left eyes). Three mice from each group $(n=3)$ were utilized for the histopathology examination as described before. The whole eyes were fixed in formalin saline solution $(10 \% \mathrm{v} / \mathrm{v}) .{ }^{27}$ After fixation, the eyes were bisected, and the specimens were dehydrated by alcohol, fixed in melted paraffin. Microtome was employed to arrange thin sections $(2 \mathrm{~mm})$, deparaffinized and pigmented by hematoxylin and eosin. A light microscope (DMS1000 B; Leica, UK) was utilized to inspect samples.

\section{Assessment of Serum Inflammatory Biomarkers}

Finally, after performing the in-vivo experiment, three mice from each group received anesthesia, and blood samples were collected into tubes via retro-orbital puncture for assessment of high-sensitivity C-reactive protein (hs-CRP) and interleukin- 1 beta (IL-1Beta) employing enzyme-linked immunosorbent assay (ELISA) according to the manufacturer's commands. ${ }^{28}$ The assay procedure was conducted by measuring the absorbance of the yellow color at $450 \mathrm{~nm}$. The sample concentration was determined from the corresponding standard curve. ${ }^{22}$

\section{Results and Discussion}

\section{Factorial Design Optimization}

Preliminary trials were carried out to detect the promising ranges of the independent variables. Independent variables that were studied for TPs: PC concentration $\left(\mathrm{X}_{1}\right)$ and terpene type $\left(\mathrm{X}_{2}\right)$ while independent variables that were studied for LPs: cationic SAA type $\left(\mathrm{X}_{1}\right)$ and PC: SAA molar ratio $\left(\mathrm{X}_{2}\right)$. EE\% $\left(\mathrm{Y}_{1}\right)$, PS $\left(\mathrm{Y}_{2}\right)$, PDI $\left(\mathrm{Y}_{3}\right)$, and $\mathrm{ZP}$ $\left(\mathrm{Y}_{4}\right)$ were selected as dependent variables. Noticing the design analysis values in Table 2, the model selected was two-factor interaction. It was noted that the predicted $R^{2}$

Table 2 Output Data of the Two Full Factorial Designs $\left(2^{\prime} .3^{\prime}\right)$ Analysis of TP and LP Formulations and the Predicted and Observed Values for the Selected TP (TP4) and LP (LPI)

\begin{tabular}{|l|c|c|c|c|}
\hline Responses & EE\% & $\begin{array}{c}\text { PS } \\
(\mathbf{n m})\end{array}$ & PDI & $\begin{array}{c}\text { ZP } \\
(\mathbf{m V})\end{array}$ \\
\hline Adequate precision (TP) & 33.46 & 10.96 & 6.08 & 26.75 \\
\hline Adjusted $R^{2}$ (TP) & 0.98 & 0.88 & 0.64 & 0.98 \\
\hline Predicted $R^{2}$ (TP) & 0.97 & 0.74 & 0.21 & 0.96 \\
\hline Significant factors (TP) & $\mathrm{X}_{1}, \mathrm{X}_{2}$ & $\mathrm{X}_{1}, \mathrm{X}_{2}$ & $\mathrm{X}_{2}$ & $\mathrm{X}_{1}, \mathrm{X}_{2}$ \\
\hline $\begin{array}{l}\text { Predicted value of selected } \\
\text { formula (TP4) }\end{array}$ & 84.18 & 578.65 & 0.56 & -12.50 \\
\hline $\begin{array}{l}\text { Observed value of selected } \\
\text { formula (TP4) }\end{array}$ & 84.14 & 578.65 & 0.56 & -12.50 \\
\hline Adequate precision (LP) & 40.77 & 41.35 & $25.5 \mathrm{I}$ & 12.06 \\
\hline Adjusted $R^{2}$ (LP) & 0.99 & 0.99 & 0.97 & 0.92 \\
\hline Predicted $R^{2}(\mathrm{LP})$ & 0.98 & 0.98 & 0.95 & 0.84 \\
\hline Significant factors (LP) & $\mathrm{X}_{1}, \mathrm{X}_{2}$ & $\mathrm{X}_{1}, \mathrm{X}_{2}$ & $\mathrm{X}_{2}$ & $\mathrm{X}_{1}, \mathrm{X}_{2}$ \\
\hline $\begin{array}{l}\text { Predicted value of selected } \\
\text { formula (LPI) }\end{array}$ & 78.47 & $102.4 \mathrm{I}$ & 0.28 & 32.50 \\
\hline $\begin{array}{l}\text { Observed value of selected } \\
\text { formula (LPI) }\end{array}$ & 78.47 & $102.4 \mathrm{I}$ & 0.28 & 32.50 \\
\hline
\end{tabular}

Abbreviations: EE\%, entrapment efficiency percentage; PS, particle size; PDI, polydispersity index; TP, terpesomes; LP, leciplex, and ZP; zeta potential. 
values were in reasonable agreement with the adjusted $R^{2}$ in all responses except PDI. The adequate precision greater than 4 is desirable, ${ }^{18}$ which was recognized in all responses as shown in Table 2.

\section{Effect of Formulation Variables on the EE\%}

The significance of the independent variables, $X_{1}$ and $X_{2}$, on the EE\% of MOX in both TPs and LPs is illustrated in Table 2. It is also graphically presented as threedimensional (3-D) surface plots in Figures (1A and 2A). $\mathrm{EE} \%$ of MOX within TPs formulations ranged from 60.45 \pm 1.05 to $85.96 \pm 0.10 \%$, as shown in Table 3 . The results showed that the increase in PC concentration $\left(\mathrm{X}_{1}\right)$ led to an increase in EE\% significantly $(p=0.0003)$. These results might be related to the surface-active properties of PC that might enhance the formation of strong coherent layers around TPs and hence might reduce the leakage of MOX. ${ }^{29}$ Moreover, a higher viscosity would be obtained upon using higher PC concentration which might minimize the external diffusion of MOX. ${ }^{10}$

Additionally, terpene type $\left(\mathrm{X}_{2}\right)$ had a significant influence $(p<0.0001)$ on EE\%. It was found that TPs with the highest $\mathrm{EE} \%$ were fabricated with fenchone followed by cineole then by limonene. These results could be ascribed to the lipophilicity of the employed terpenes as revealed by their $\log \mathrm{P}$ values $\log \mathrm{P}=2.13,2.82$, and 4.83 for fenchone, cineole, and limonene, respectively. ${ }^{29}$ Previous studies revealed that higher entrapment efficiency for the lipophilic drug as dapsone and finasteride was obtained using a terpene with high lipophilicity. ${ }^{30,31}$ On the contrary, in this study results, can be inferred as MOX being a hydrophilic drug, has higher entrapment efficiency when combined with fenchone having lower lipophilicity. These findings agree with Vidya et al, who found that the EE\% of hydrophilic drug anastrozole increased in the presence of fenchone compared to more lipophilic terpene. ${ }^{31}$ Also, the electrostatic attraction between the amino group of MOX, positively charged at $\mathrm{pH}$ 7.4, and the carbonyl group in fenchone could also contribute to a higher $\mathrm{EE} \%$ of MOX in the fenchone based formulae. ${ }^{32}$

For LPs formulations, EE\% ranged from $74.02 \pm 0.79$ to $96.85 \pm 0.21 \%$, as shown in Table 3. SAA type $\left(\mathrm{X}_{1}\right)$ had a significant influence $(p<0.0001)$ on EE\% of LPs, in which the highest $\mathrm{EE} \%$ was found in LPs with $\mathrm{CTAB}$ rather than DDAB. These results could be attributed to the difference in the lipophilicity between CTAB and DDAB, where CTAB with the lowest lipophilicity ( $\log \mathrm{P}=8)$ could help in entrapping MOX (hydrophilic drug) more than DDAB with higher lipophilicity $(\log \mathrm{P}=11.8) .{ }^{33}$ The results also indicated
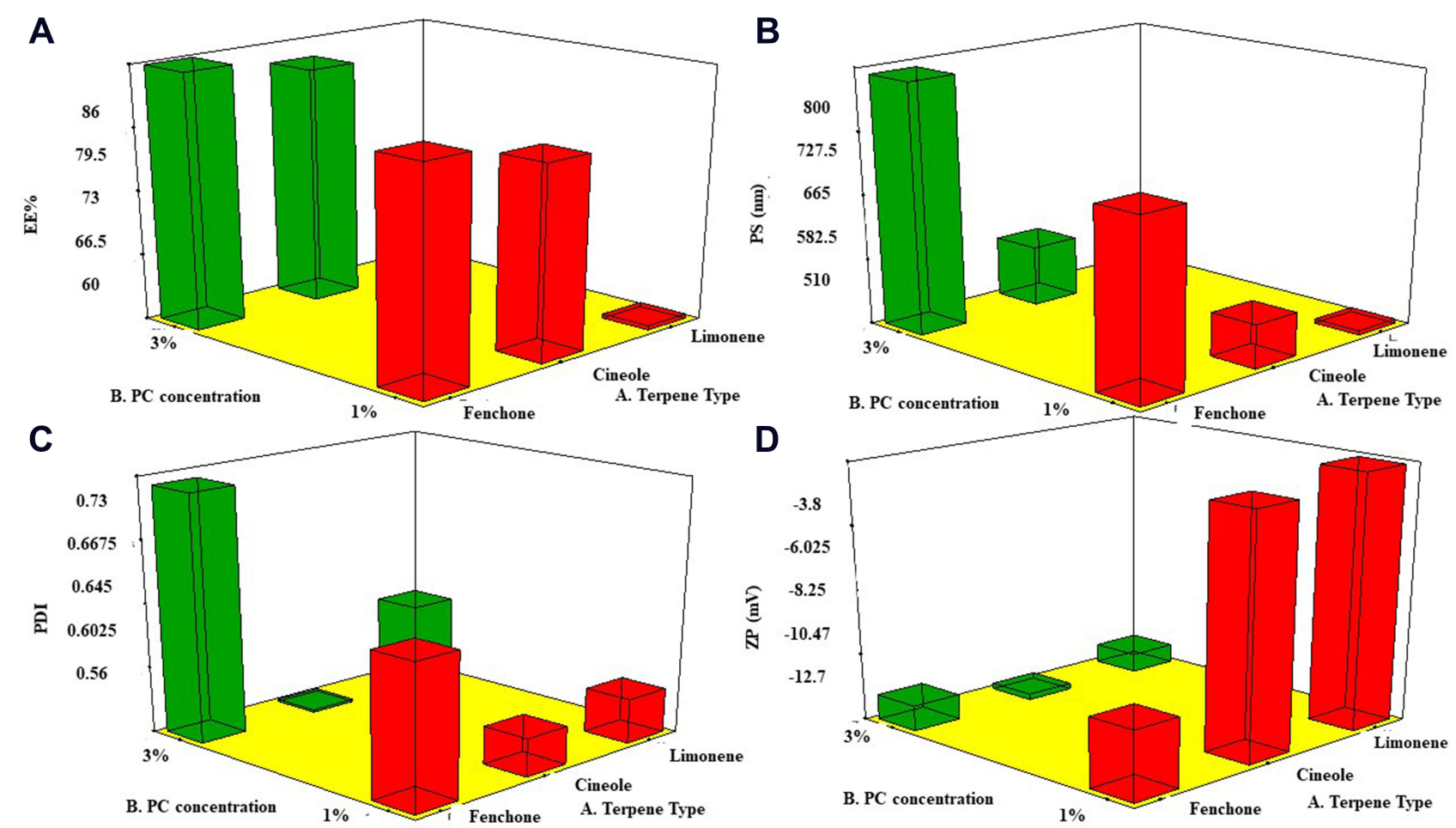

Figure I Response 3D plots for the effect of PC ratio $\left(X_{1}\right)$ and terpene type $\left(X_{2}\right)$ on $(\mathbf{A})$ EE\%, (B) PS, (C) PDI and (D) ZP of MOX loaded TPs.

Abbreviations: EE\%, entrapment efficiency percent; PS, particle size; PDI, polydispersity index; ZP, zeta potential; MOX, moxifloxacin hydrochloride; TP, terpesomes. 

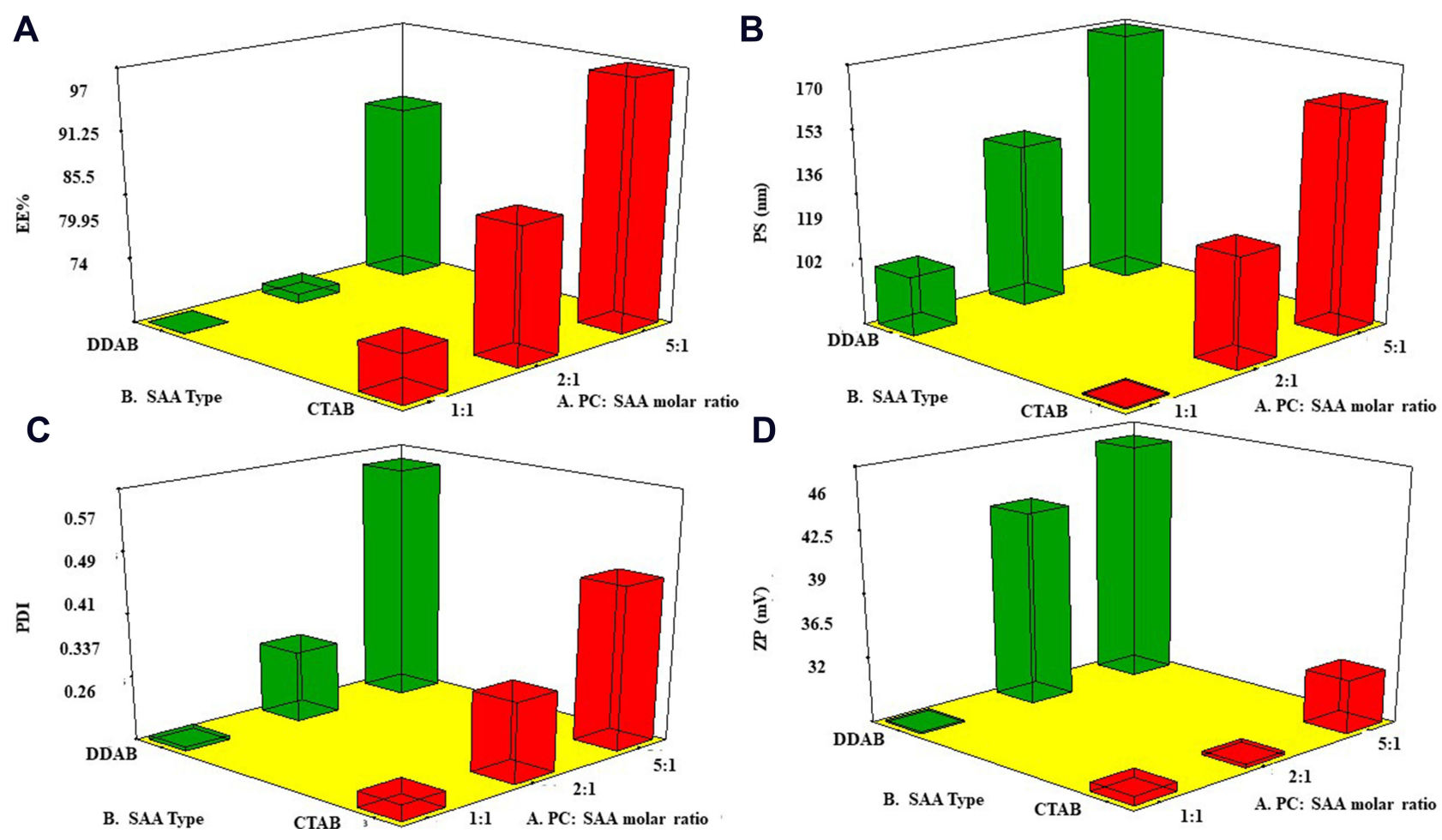

Figure 2 Response 3D plots for the effect of SAA type $\left(X_{1}\right)$ and PC: SAA molar ratio $\left(X_{2}\right)$ on $(\mathbf{A})$ EE\%, (B) PS, (C) PDI and (D) ZP of MOX loaded LPs.

Abbreviations: EE\%, entrapment efficiency percent; PS, particle size; PDI, polydispersity index; ZP, zeta potential; SAA, surfactant; MOX, moxifloxacin hydrochloride; LP, leciplex.

that PC: SAA molar ratio $\left(\mathrm{X}_{2}\right)$ significantly affected $\mathrm{EE} \%(\mathrm{p}$ $<0.0001$ ) by a direct positive relationship which may be due to PC solubilization by SAA, leading to drug leakage from
LPs when they have the same molar ratio but when PC increased, SAA will not be enough to solubilize PC leading to the development of the tight bilayers and EE\% increased. ${ }^{9}$

Table 3 Experimental Runs, Independent Variables, and Measured Response of the $2^{\prime} .3^{\prime}$ Full Factorial Experimental Design of MOX Loaded TPs and LPs.

\begin{tabular}{|c|c|c|c|c|c|c|}
\hline $\begin{array}{l}\text { Formulation Code of } \\
\text { TPs }\end{array}$ & $\begin{array}{c}\text { PC Concentration } \\
\left(\mathbf{X}_{1}\right)\end{array}$ & Terpene Type $\left(\mathbf{X}_{2}\right)$ & EE\% & PS (nm) & PDI & ZP $(\mathbf{m V})$ \\
\hline TPI & $1 \%$ & Fenchone & $82.32 \pm 0.80$ & $711.10 \pm 61.10$ & $0.65 \pm 0.03$ & $-10.30 \pm 0.50$ \\
\hline TP2 & $3 \%$ & Fenchone & $85.96 \pm 0.10$ & $793.65 \pm 8.85$ & $0.72 \pm 0.01$ & $-11.82 \pm 0.50$ \\
\hline TP3 & $1 \%$ & Cineole & $79.70 \pm 0.06$ & $560.10 \pm 1.30$ & $0.58 \pm 0.01$ & $-4.31 \pm 0.06$ \\
\hline TP4 & $3 \%$ & Cineole & $84.14 \pm 0.21$ & $578.65 \pm 5.65$ & $0.56 \pm 0.04$ & $-12.50 \pm 0.30$ \\
\hline TP5 & $1 \%$ & Limonene & $60.45 \pm 1.05$ & $515.00 \pm 5.00$ & $0.59 \pm 0.027$ & $-3.87 \pm 0.08$ \\
\hline TP6 & $3 \%$ & Limonene & $66.22 \pm 1.29$ & $568.35 \pm 1.15$ & $0.6 I \pm 0.07$ & $-12.05 \pm 0.15$ \\
\hline $\begin{array}{l}\text { Formulation Code of } \\
\text { LPs }\end{array}$ & SAA Type $\left(X_{1}\right)$ & $\begin{array}{c}\text { PC: SAA Molar Ratio } \\
\qquad\left(\mathbf{X}_{2}\right)\end{array}$ & EE\% & PS (nm) & PDI & ZP $(\mathbf{m V})$ \\
\hline LPI & CTAB & I:I & $78.47 \pm 0.17$ & $102.41 \pm 3.39$ & $0.28 \pm 0.0 \mathrm{I}$ & $32.50 \pm 0.50$ \\
\hline LP2 & DDAB & I:I & $74.02 \pm 0.79$ & $117.75 \pm 0.95$ & $0.26 \pm 0.005$ & $32.10 \pm 0.70$ \\
\hline LP3 & CTAB & $2: 1$ & $86.50 \pm 0.85$ & $|3| .2| \pm| .2 \mid$ & $0.36 \pm 0.02$ & $32.20 \pm 2.20$ \\
\hline LP4 & DDAB & $2: 1$ & $74.87 \pm 0.66$ & $|45.3| \pm 0.66$ & $0.34 \pm 0.0005$ & $42.80 \pm 0.80$ \\
\hline LP5 & CTAB & $5: 1$ & $96.85 \pm 0.21$ & $161.05 \pm 1.05$ & $0.46 \pm 0.005$ & $35.00 \pm 1.00$ \\
\hline LP6 & DDAB & $5: 1$ & $90.20 \pm 0.07$ & $169.35 \pm 0.55$ & $0.55 \pm 0.01$ & $45.35 \pm 0.15$ \\
\hline
\end{tabular}

Note: Data represented as mean $\pm S D(n=3)$.

Abbreviations: EE\%, entrapment efficiency percentage; LP, leciplex; MOX, moxifloxacin hydrochloride; PC, phospholipid; PS, particle size; PDI, polydispersity index; TP, terpesomes, and ZP, zeta potential. 


\section{Effect of Formulation Variables on the PS}

PS of TPs ranged from $515.00 \pm 5.00$ to $793.65 \pm 8.85 \mathrm{~nm}$, as displayed in Table 3 and Figure 1B. ANOVA results provide that both $X_{1}$ and $X_{2}$ had a significant influence on the PS of the prepared TPs. PC concentration $\left(\mathrm{X}_{1}\right)$ positively impacted the PS $(p=0.0477)$, where increasing PC concentration resulted in larger PS of the prepared TPs. These findings agree with the results of $\mathrm{EE} \%$, where increasing PC concentration resulted in a higher entrapment of MOX in TPs. Regarding terpene type $\left(\mathrm{X}_{2}\right)$, an inverse relation was found between PS and the lipophilicity of the used terpenes at a $p$-value $=0.0003$. TPs prepared using fenchone had the largest PS compared to other TPs prepared with other terpenes. These results may be due to the low lipophilicity of fenchone, resulting in a high repulsion force between the hydrophilic terpene and lipophilic nature of the vesicular system. Correspondingly, TPs prepared using limonene had the smallest PS due to the highest lipophilicity of limonene. ${ }^{10}$

In addition, PS of LPs formulations ranged from 102.41 \pm 3.39 to $169.35 \pm 0.55 \mathrm{~nm}$, as shown in Table 3 and Figure 2B. Both $X_{1}$ and $X_{2}$ had a significant effect on the PS of the LPs, at a p-value $<0.0001$. Considering $\mathrm{X}_{1}$ (SAA type), smaller vesicles were obtained by single chained cationic surfactant CTAB compared to those formulated by double-chained surfactant DDAB, similar results were found by Date et al. ${ }^{12}$ For $\mathrm{X}_{2}$ (PC: SAA molar ratio), larger vesicles were obtained at high PC: SAA molar ratio. These results could be due to that at a high PC level, the amount of SAA will be not enough to lower the interfacial tension leading to the formation of larger LPs. ${ }^{34}$

\section{Effect of Formulation Variables on the PDI}

The values of PDI ranged between $0.56 \pm 0.04$ and 0.72 \pm 0.01 for all TPs formulations, as shown in Table 3 and Figure 1C. These results indicate that the prepared TPs were polydisperse but within acceptable limits. ${ }^{6}$ It was found that only terpene type $\left(\mathrm{X}_{2}\right)$ significantly affects PDI, at a p-value $=0.0188$ in which a direct correlation was detected between the PS and the PDI where the highest PDI value was found in vesicles that had the largest PS, and this is in agreement with Tawfik et al ${ }^{35}$. While regarding LPs formulations, PDI values ranged from $0.26 \pm 0.005$ to $0.55 \pm 0.01$ as displayed in Table 3 and Figure $2 \mathrm{C}$. Results revealed that only $\mathrm{X}_{2}$ (PC: SAA molar ratio) had a significant positive effect on PDI with a p-value
$<0.0001$, which could be attributed to the high viscosity of the dispersed phase at high PC concentration, which led to particle aggregation and consequently increased the PS and PDI and reduced homogenization of LPs dispersion. ${ }^{36}$

\section{Effect of Formulation Variables on the ZP}

$\mathrm{ZP}$ values of all the prepared TPs showed a negative charge and ranged from $-3.87 \pm 0.08$ to $-12.50 \pm 0.15 \mathrm{mV}$, as shown in Table 3 and Figure 1D. ANOVA results showed that both $X_{1}$ and $X_{2}$ had a significant influence on the ZP of theTPs with $p$ values of $<0.0001$ and 0.0001 , respectively. Using $\mathrm{PC}$ at a high concentration would increase ZP values. It was assumed that in a medium of low ionic strength, the polar head group is directed in a way that the negatively charged phosphatidyl group is oriented to the outside while the positively charged choline group is placed to the inside leading to a net negative charge on the surface. ${ }^{29}$ On the other hand, TPs fabricated with fenchone showed higher ZP values than those fabricated with other terpenes, which may be due to its higher $\mathrm{EE} \%$, as discussed before. It was previously reported that increasing drug EE\% results in increasing charges attained by the vesicles due to its ionization in neutral or alkaline pH into a negatively charged molecule. ${ }^{37}$

While all LPs formulae revealed positive surface charge ( $32.10 \pm 0.70$ to $45.35 \pm 0.15 \mathrm{mV}$ ) (Figure 2D), indicating good colloidal stability, the privileged positive charge for these formulae enhanced the electrostatic interaction between cationic LPs and the negatively charged sialic acid residues of corneal mucins. ${ }^{8}$ Both independent variables $\left(\mathrm{X}_{1}\right.$ and $\left.\mathrm{X}_{2}\right)$ showed significant effects on $\mathrm{ZP}$ with $p$ values of 0.0003 and 0.001 , respectively. Regarding $\mathrm{X}_{1}$, it was found that DDAB formulae showed highest ZP values than $\mathrm{CTAB}$ formulae revealing stabilizing effect of cationic surfactant $\mathrm{DDAB}$, and this result following Hassan et $\mathrm{al}^{8}$. For $\mathrm{X}_{2}$, it was found that a high PC: SAA molar ratio led to a higher positive charge and hence higher ZP values.

\section{Selection of the Optimized Formulae}

To select the optimized formulae, certain conditions were set in Design Expert ${ }^{\circledR}$ software version 11. These conditions favored nanovesicles with the highest EE\%, ZP (as absolute value), and lowest PS and PDI. The optimized formula that met these criteria regarding TPs formulation was composed of cineole as terpene type and had a PC concentration of $3 \%$. TPs optimized formula (TP4) showed an EE\% of $84.14 \pm 0.21 \%$, a PS of $578.65 \pm 5.65$ 
$\mathrm{nm}$, a PDI of $0.56 \pm 0.04$, and a ZP of $-12.5 \pm 0.30 \mathrm{mV}$. On the other hand, LPs optimized formula, which was proposed to be prepared, was found to include PC: SAA molar ratio of $1: 1$ and $\mathrm{CTAB}$ as SAA. LPs optimized formula (LP1) revealed an $\mathrm{EE} \%$ of $78.47 \pm 0.17 \%$, a PS of $102.41 \pm 3.39 \mathrm{~nm}$, a PDI of $0.28 \pm 0.01$, and a ZP of 32.50 $\pm 0.50 \mathrm{mV}$. To validate the experimental design, the predicted and observed responses of TP4 and LP1 were correlated and are shown in Table 2. A high correlation was observed between the observed and predicted values. Subsequently, TP4 and LP1 were selected as the optimized formulae for further inspection.

\section{Ex-vivo Studies}

\section{Ex-vivo Permeation Studies}

From Figure 3, it could be concluded that the quantity of MOX permeated from LP1 was significantly $(\mathrm{P} \geq 0.5)$ greater than that permeated from TP4 and MOX solution. These results may be due to LPs' cationic nature, which enhances binding to the negatively charged mucus and enhances the retention time. ${ }^{38}$ Similarly, PS affects the drug permeation. The smaller the PS, the higher the interfacial area accessible for drug exchange which facilitated their delivery through the hydrated network of the corneal stroma and accordingly enhances drug efficacy. ${ }^{39}$ The ER was more than 7.97 times for LP1 and more than 2.23 for TP4 compared to MOX solution, as illustrated in Table 4. The significant higher permeability across the cornea from LP1 and TP4 compared to MOX solution may be related to the agglomeration of vesicles as a depot near the cornea from which the drug is slowly delivered to the precorneal area, as previously reported by Mudgil et al. ${ }^{40}$

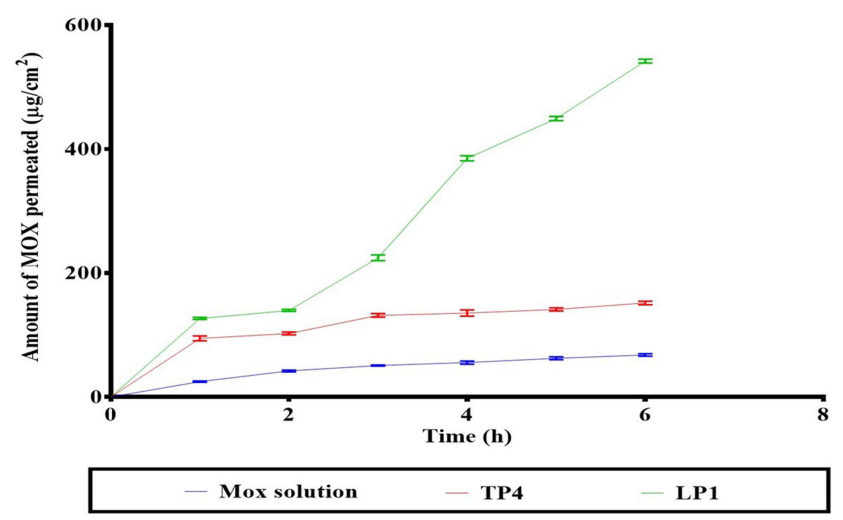

Figure 3 Cumulative amount of MOX permeated per unit area across excised cow cornea via TP4 and LPI relative to MOX solution.

Abbreviations: MOX, moxifloxacin hydrochloride; TP, terpesomes; LP, leciplex.
Table 4 Corneal Permeability Parameters of MOX After Application of MOX Solution, TP4, and LPI

\begin{tabular}{|l|c|c|c|}
\hline $\begin{array}{l}\text { Corneal } \\
\text { Permeability } \\
\text { Parameters }\end{array}$ & $\begin{array}{c}\text { MOX } \\
\text { Solution }\end{array}$ & TP4 & LPI \\
\hline $\begin{array}{l}\text { Total amount of MOX } \\
\text { permeated per unit } \\
\text { area after } 6 \mathrm{~h}\left(\mu \mathrm{g} / \mathrm{cm}^{2}\right)\end{array}$ & $67.93 \pm 1.95$ & $151.77 \pm 2.75$ & $541.94 \pm 3.04$ \\
\hline$J_{\max }\left(\mu \mathrm{g} / \mathrm{cm}^{2} / \mathrm{h}\right)$ & $11.32 \pm 0.32$ & $25.29 \pm 0.45$ & $90.32 \pm 0.50$ \\
\hline ER & $\mathrm{I}$ & 2.23 & 7.97 \\
\hline
\end{tabular}

Note: Data are presented as mean \pm SD $(n=3)$.

Abbreviations: $\int_{\max }$, permeation flux; ER, enhancement ratio; MOX, moxifloxacin hydrochloride; TP, terpesome; LP, leciplex.

\section{CLSM}

CLSM was assessed to estimate the potency of infiltration and fluorescence light intensity following ocular delivery of fluoro-labeled TPs and LPs. Images gained with CLSM (Figures 4 and 5) showed that the FDAloaded TPs and LPs exhibited deposition of fluorescence in various eye layers. Scans were taken from the longitudinal section that supplied information about the penetration depth of nanovesicles in corneal tissues. Both nanovesicles showed homogeneous diffusion on the corneal tissues; however, by calculating the maximum intensity of fluorescent light, there was a significant $(\mathrm{P} \geq 0.5)$ difference between the TPs and LPs as the average intensity was $9119.81 \pm 565.01$ and $26804.23 \pm 1615.27$ for TPs and LPs, respectively. It is worth noting that CLSM results supported ex-vivo permeation results. Therefore, the previous findings could be justified to the smaller PS of LPs compared to TPs that might aid the nanovesicles to penetrate extensively in the corneal tissues as previously discussed.

\section{Morphology}

Morphological analysis of the selected LP formula is given in Figure 6. The TEM image indicated that LP1 was spherical and had a uniform distribution. The PS of the LPs determined by Zetasizer was in good agreement with TEM observations.

\section{Stability Study}

LP1 was subjected to a short-term stability study for three months. The visual inspection of the LP1 did not demonstrate any sedimentation or vesicles' aggregation during the storage period. The EE\%, PS, PDI, and zeta potential 


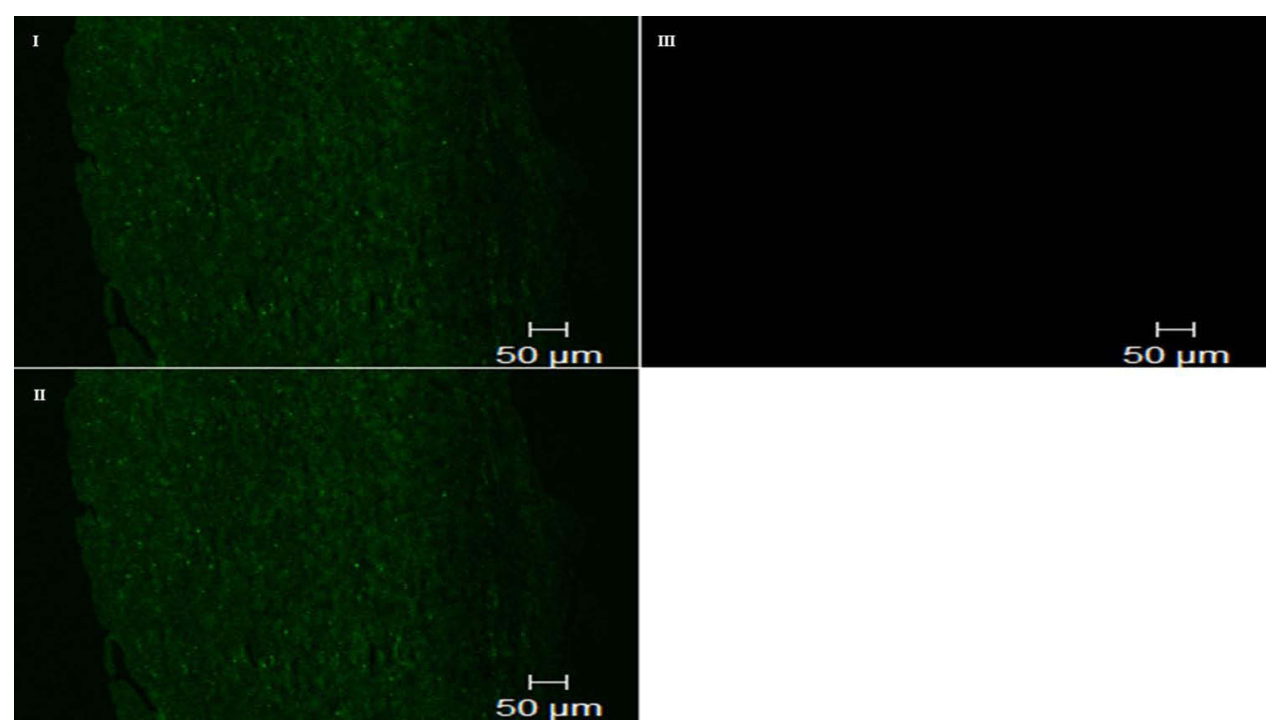

Figure $4 \mathrm{~A}$ tile scan confocal laser microscope photomicrograph of longitudinal section in cow cornea treated with FDA loaded TPs I) Fluorescence light, II) transmitted light and III) merge between fluorescence light and transmitted light.

Abbreviations: FDA, fluorescein diacetate; TPs, terpesomes.

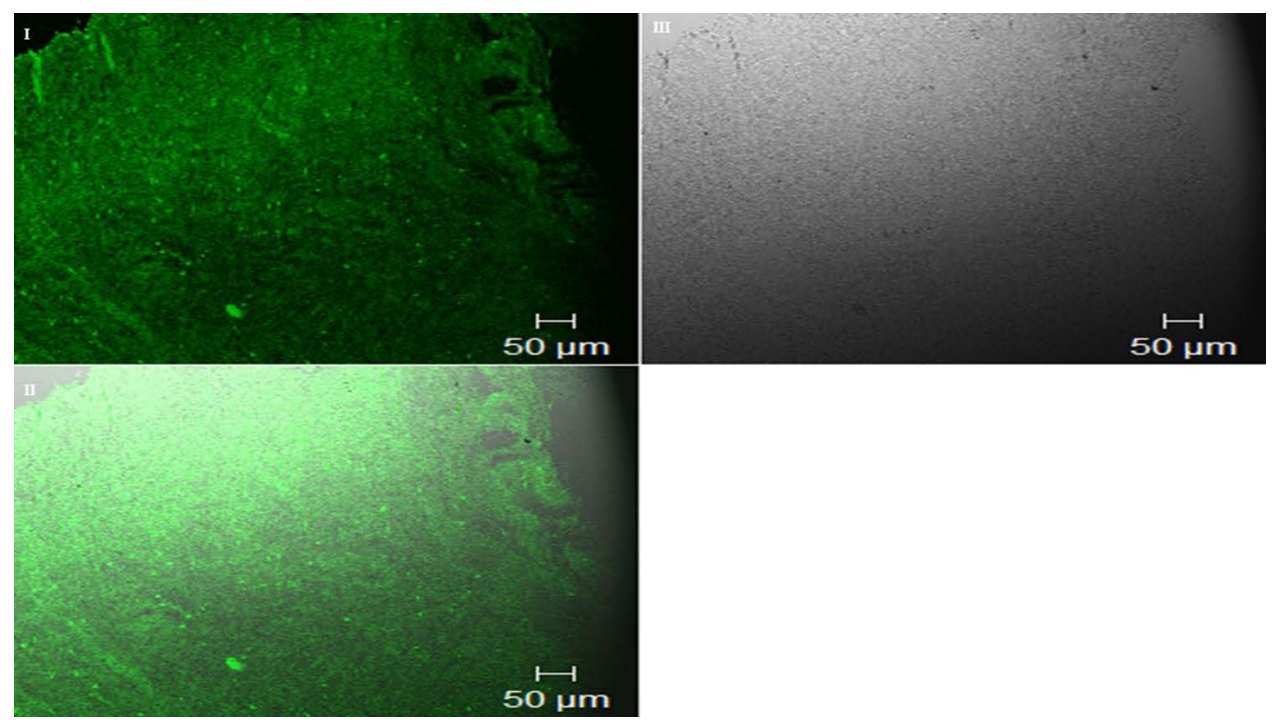

Figure 5 A tile scan confocal laser microscope photomicrograph of longitudinal section in cow cornea treated with FDA loaded LPs I) Fluorescence light, II) transmitted light and III) merge between fluorescence light and transmitted light.

Abbreviations: FDA, fluorescein diacetate; LPs, leciplex.

measurements of LP1 were $76.43 \pm 6.30 \%, 100.00 \pm 3.00$ $\mathrm{nm}, 0.301 \pm 0.02$, and $34.00 \pm 0.07 \mathrm{mV}$, respectively, which showed insignificant variation from the freshly prepared LPs $(p>0.05)$. These findings revealed the physical stability of the formulated LP1, which may be related to the presence of CTAB that gives a high positive charge on the vesicle. The charge of the nanovesicles is a fundamental property that can influence vesicular aspects. Electrostatic repulsion can prohibit the mutual agglomeration, fusion of vesicles, and promote vesicles' stability. ${ }^{41}$

\section{$\mathrm{pH}$ Measurement}

$\mathrm{pH}$ values of LP1 were found to be $7.10 \pm 0.12$ implying the convenience of LP1 for ocular utilization $(\mathrm{pH}$ of tears $=7.4)^{23}$

\section{Evaluation of Mucoadhesion Properties of Mucoadhesive Nanovesicles}

The ZP of the mucin suspension was $-9.77 \mathrm{mV} \pm 0.53$ changed upon mixing with mucoadhesive leciplex (LP1). 


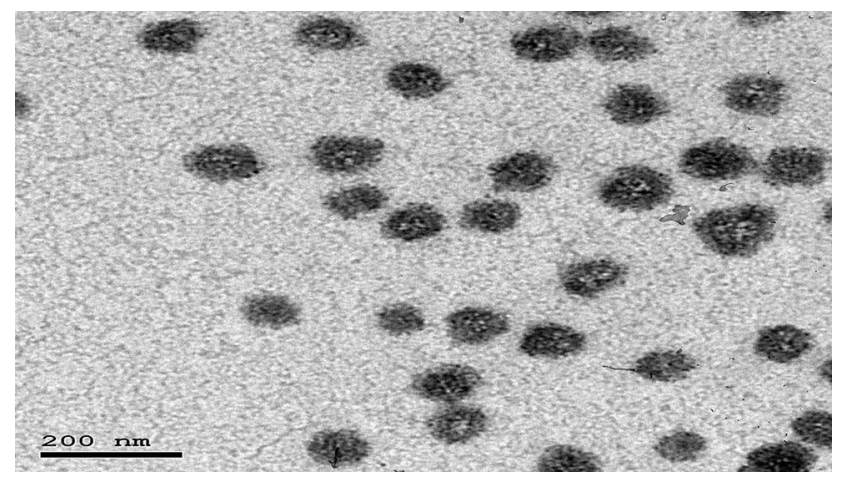

Figure 6 Morphology of the selected LPs. Abbreviation: LPs, leciplex.

A positive value was obtained from the complexes formed between mucin and LP1, where the negative charge of the mucin would be neutralized with the positive charge of the LP1 adhered on their surface. Takeuchi et al found that the component adhesion might alter the surface properties of the mucin if this component possesses a mucoadhesive property. ${ }^{42}$ Mucoadhesive LP1 showed a shift from negative mucin values to positive $10.66 \pm$ $0.59 \mathrm{mV}$ of mucin $\mathrm{ZP}$ value.

\section{In-vivo Studies}

\section{MIC and Anti-Biofilm Assays}

Highly virulent MRSA USA300 was used as the test organism in all the experiments in this study. MOX LPs and MOX solution were tested for their in-vitro antibacterial activity against MRSA USA300. Both MOX LPs and MOX solution recorded the same MIC $(0.15625 \mu \mathrm{g} / \mathrm{mL})$ with no effect of the LPs on the antibacterial activity of MOX against MRSA USA300. These results were in agreement with previous studies that reported no negative effect of drug entrapment and using LPs delivery system on the antimicrobial activity. ${ }^{43}$ Biofilm formation by various pathogenic bacteria plays an essential role in persistent infections and increases the pathogen's resistance to different antimicrobial agents. Hence the ability of the antimicrobial agent to inhibit and eradicate biofilm is essential for the treatment of resistant pathogens rather than solely on growth inhibition. ${ }^{25}$ Owing to the substantial role of biofilm in aggravating Staphylococcal corneal infections, ${ }^{2,44}$ we tested the effect of the LPs on the anti-biofilm activity of MOX. We compared the antibiofilm activity of MOX LPs to that of MOX solution at concentrations below the determined MIC $(0.078125-$
$0.00061 \mu \mathrm{g} / \mathrm{mL}$ ). MOX LPs and MOX solution significantly inhibited MRSA USA300 biofilm formation at all the tested concentrations (Two-way ANOVA, Dunnett's post-test, $P<0.0001)$. Although MOX LPs showed higher biofilm inhibition activity than MOX solution, there was no significant difference in the inhibition potency against MRSA USA300 biofilm formation at all the tested concentrations (Two-way ANOVA, Sidak's post-test, $P<0.05$ ) (Figure 7A).

On the other hand, MOX LPs viewed significantly higher biofilm eradication activity than MOX solution against the previously established MRSA USA300 biofilm at all the tested concentrations (Two-way ANOVA, Sidak's post-test, $P<0.005$ ) (Figure 7B). The biofilm act as a protective barrier for the bacteria versus the activity of the antibiotic. ${ }^{25}$ The superiority of MOX LPs in eradicating the already established biofilm may be attributed to the ability of the LPs to be adsorbed on the surface of the biofilm, which may be due to the strong affinity between the positively charged LPs and the negatively charged bacterial cell membrane, thus giving a higher chance to the released antibiotic to penetrate the biofilm thus potentiating its antibacterial activity. ${ }^{45}$ The smaller PS of the LPs might also permit higher contact with the microbial surface and enhance the antibacterial activity.

\section{In-vivo Evaluation of MOX LPs Against MRSA Corneal Infection in Mice}

A murine MRSA corneal infection model was established to evaluate the in-vivo antibacterial activity of the MOX LPs. The MOX LPs retained their antibacterial activity in-vivo with superior activity when compared to the MOX solution. Treatment with MOX LPs or MOX solution significantly decreased the bacterial number of MRSA USA300 compared to the negative untreated control (Kruskal-Wallis test, Dunn's post-test, $P<0.001$ ) (Figure 8). MOX LPs showed significantly higher antibacterial activity than MOX solution (Kruskal-Wallis test, Dunn's post-test, $P<0.0001$ ) (Figure 8). The bacterial count recovered from the MOX LPs and MOX solution treated eyes was 2.1 and $0.8 \operatorname{logs}$ lower than that of the negative control eyes, respectively. The bacterial count recovered from the MOX LPs treated eyes was $1.3 \operatorname{logs}$ lower than that of the MOX solution treated eyes. The enhanced biofilm eradication activity of MOX LPs might have played a role in the superiority of MOX LPs in significantly 

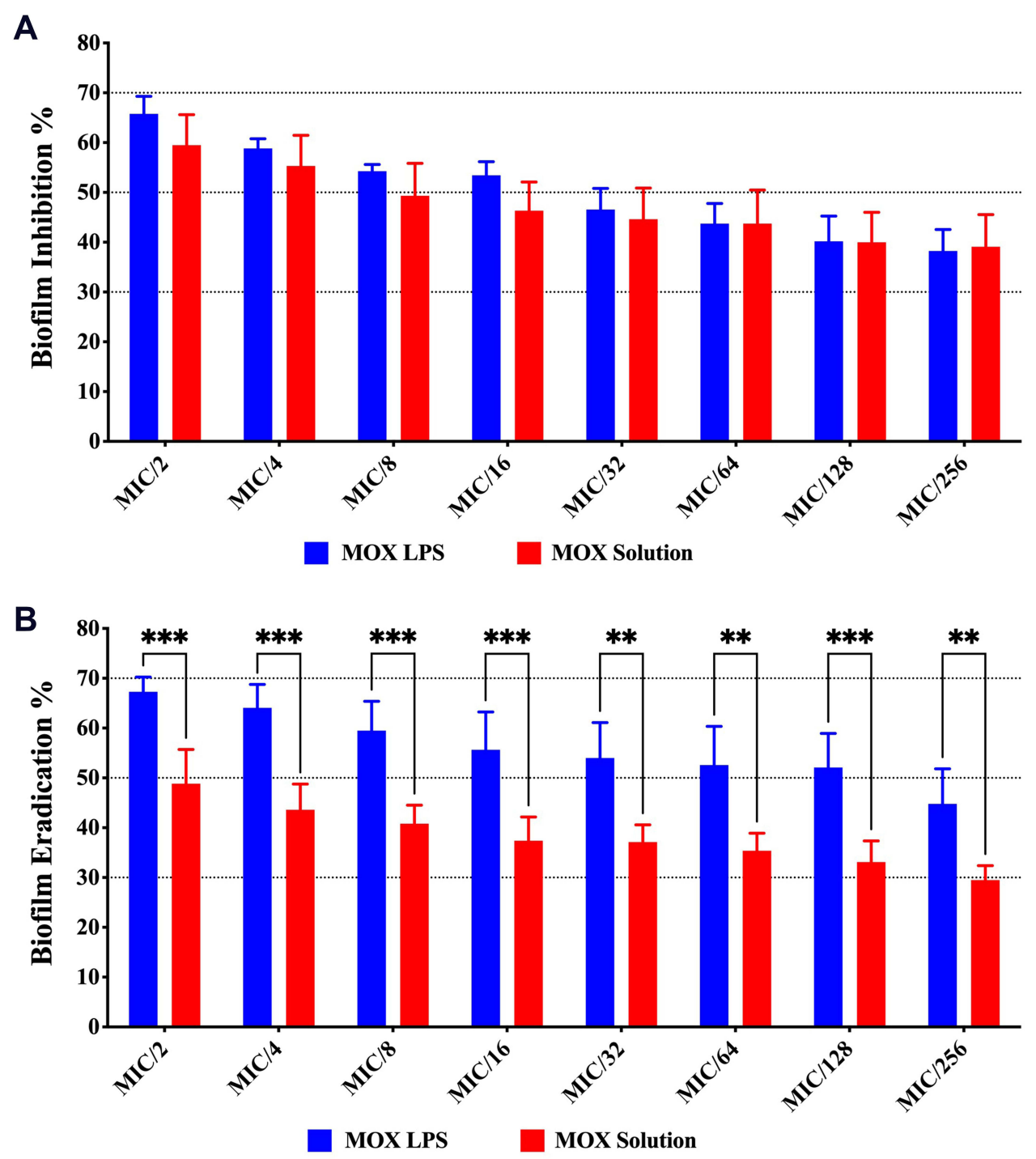

Figure 7 The effect of MOX LPs and MOX solution against methicillin-resistant Staphylococcus aureus (MRSA USA300) biofilm. Results are expressed as mean biofilm inhibition/eradication $\% \pm$ standard error. $* * \& * *$ Indicate that the difference is significant at $p \leq 0.0009 \& p \leq 0.005$, respectively, (Two-way ANOVA, Sidak's post-test). (A) biofilm inhibition (B) biofilm eradication.

Abbreviations: MOX, moxifloxacin hydrochloride; LPs, leciplex.

reducing the bacterial load in the treated mice's eyes. The superiority of MOX LPs in the in-vivo corneal infection model might also be attributed to the nature of the LPs and smaller PS that contributed to better corneal retention with more effective corneal contact and enhanced MOX bioavailability. Our findings comply with previous studies which have reported that drug entrapment into nanoparticles enhanced drug pharmacokinetics in the aqueous humor, ${ }^{6,8,46}$ promoting the application of LPs as an effective ocular delivery system. It is worth noting that the existence of CTAB enhanced the antibacterial effect of MOX-loaded LPs compared to MOX solution as it has an antibacterial effect, as previously reported. ${ }^{47}$ Furthermore, histopathological evaluation of ocular tissues was performed and showed light microscopy inspection of stained sections. For positive control group I: The covering epithelial cell layer showed stratification while the underlying stroma was intact; in addition, there was no histopathological alteration as recorded in Figure 9. There was no histopathological alteration in the cornea, retina, or sclera for groups II and III. The gained findings proposed that LPs have a good safety profile, as there was no clear evidence of eye intolerability found in the in-vivo assessment; therefore, it might cause no ocular irritation in clinical trials. 


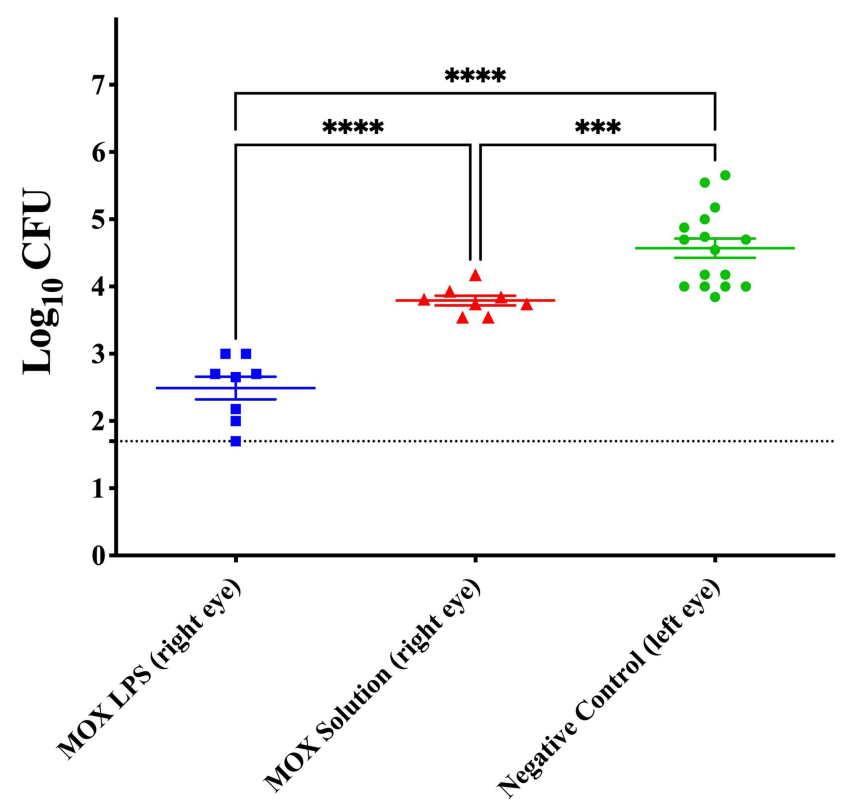

Figure 8 Efficacy of MOX LPs and MOX solution in in-vivo murine model of MRSA corneal infection. Sixteen male BALB/C mice were divided into two groups $(n=8)$. The right eyes were treated topically with either MOX LPs $(0.5 \% \mathrm{w} / \mathrm{v})$ or MOX solution $(0.5$ $\% \mathrm{w} / \mathrm{v})$. The left eye of each mouse did not receive any treatment and served as the untreated negative control. The scatter plot shows the efficacy of MOX LPs/solution on the bacterial load in the murine model of MRSA corneal infection. Results are expressed as mean \pm standard error. The dotted line represents the limit of detection of the viable count $(\log 10$ of $50 \mathrm{CFU}=1.699)$. $* * * * * * * *$ Indicate that the difference is significant at $p<0.000$ I \& $p \leq 0.0009$, respectively, (Kruskal-Wallis test, Dunn's post-test).

Abbreviation: MOX, moxifloxacin hydrochloride; LPs, leciplex.

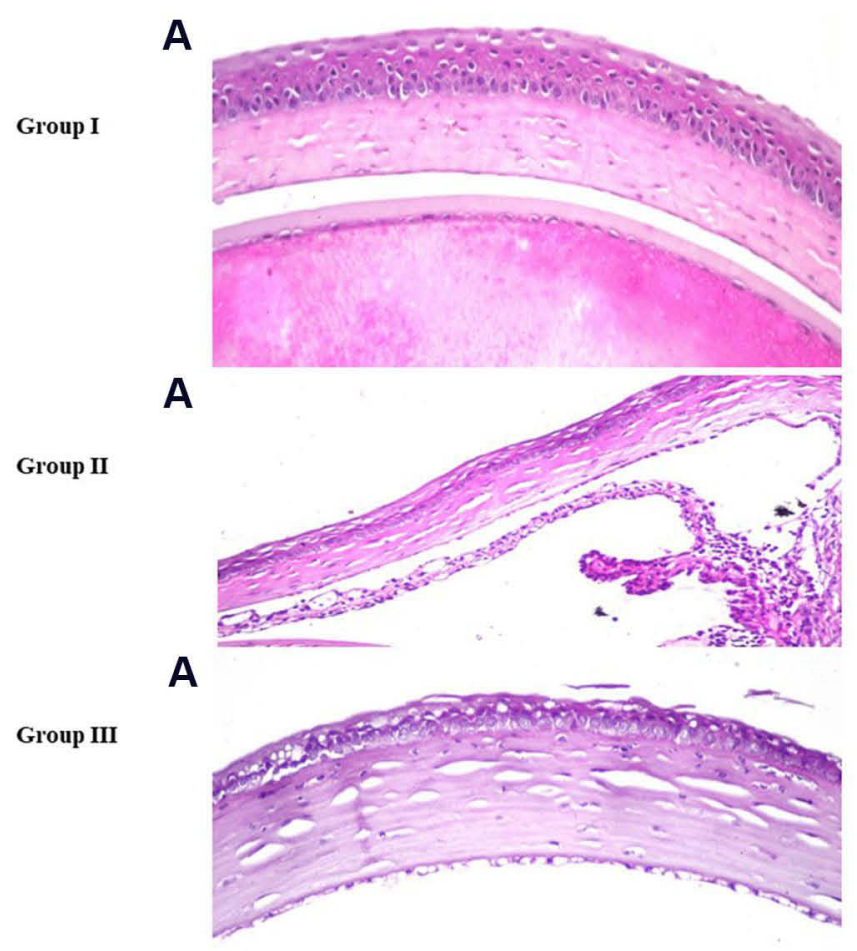

\section{Assessment of Serum Inflammatory Biomarkers}

Cytokines and other mediators play essential roles in eye inflammation. ${ }^{48}$ In this study, we examined the secretion of two inflammatory mediators, IL-1Beta and hs- CRP, in mice treated with MOX-LPs and MOX solution to determine their inflammation or irritation effect. It was found that mice with MRSA corneal infection, which were treated with MOX LPs and MOX solution, did not show any significant increase in the serum level of these inflammatory cytokines (IL-1Beta and hs-CRP) compared to a negative control (without treatment or infection) (Figure 10). These findings confirmed our proposed formulation's good safety profile, which is in good agreement with the histopathological evaluation results.

\section{Conclusion}

In this study, MOX (a highly water-soluble drug) was successfully encapsulated into different lipid-based vesicles, namely, leciplex and terpesomes. Cationic leciplex achieved superiority compared to negatively charged vesicles (terpesomes) in entrapment efficiency, particle size, zeta potential, and ex-vivo studies. The results of ex-vivo and in-vivo studies point to the success of positively charged vesicles in delivering

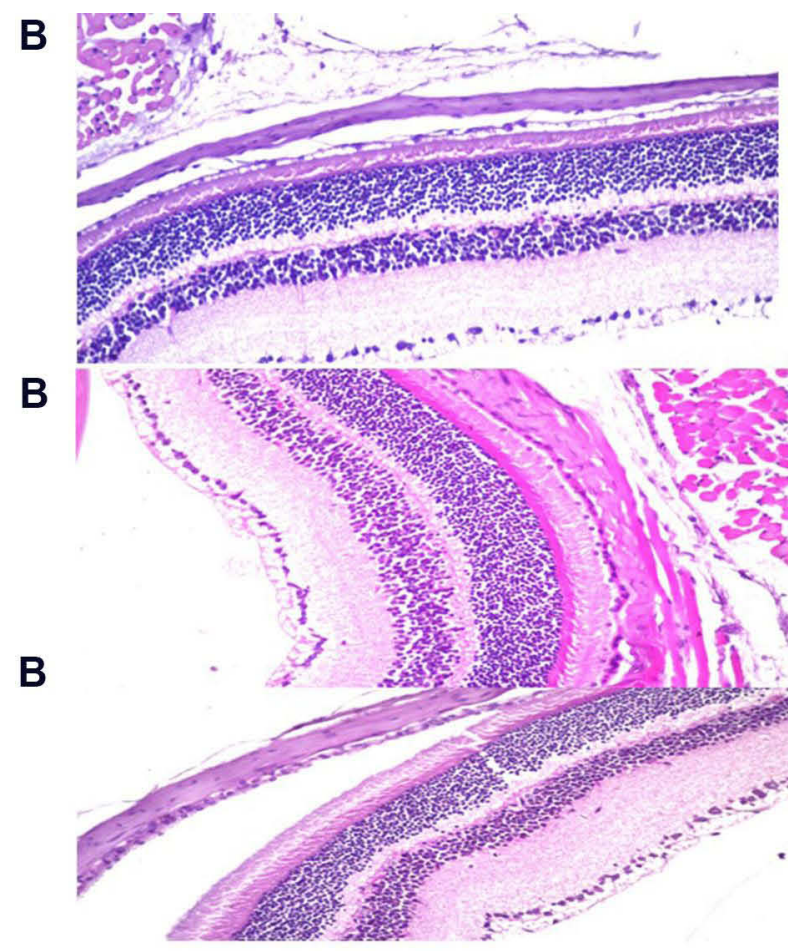

Figure 9 Photomicrographs showing histopathological sections (hematoxylin and eosin stained) of normal untreated mice eye (group I), mice eye treated with MOX solution (group II) and mice eye treated with MOX LPs (group III) (A) illustrates histological structure of the cornea and (B) illustrates histological structure of the retina, choroid and sclera. Abbreviations: MOX, moxifloxacin hydrochloride; LPs, leciplex. 

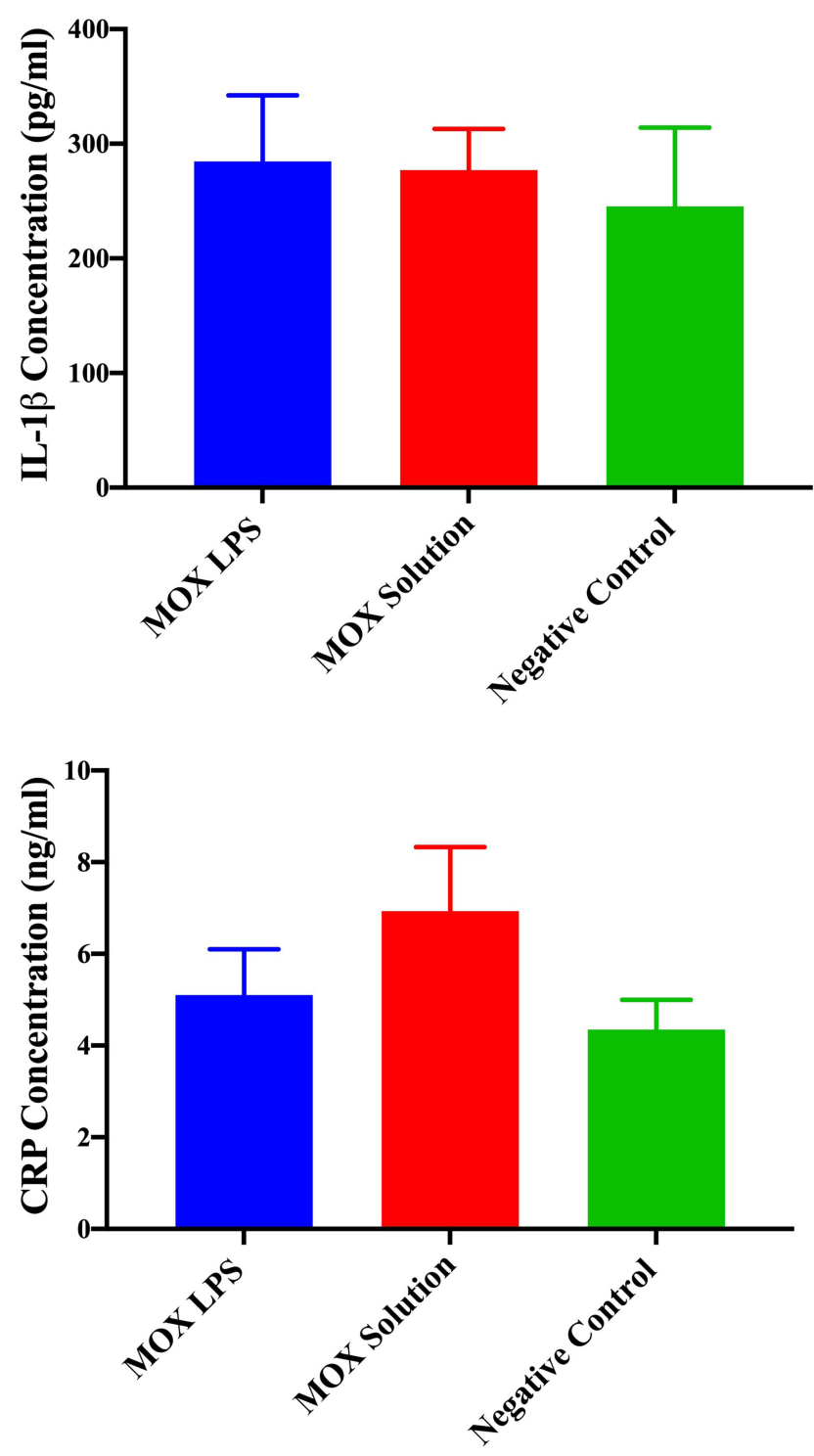

Figure 10 Assessment of serum level of inflammatory cytokines (IL-IBeta and hsCRP) in mice treated with MOX solution and MOX loaded LPs.

Abbreviations: MOX, moxifloxacin hydrochloride; IL-IBeta, interleukin I-beta; hs-CRP, high sensitive c-reactive protein; LPs, leciplex.

antimicrobial agents through complicated ocular anatomy. Furthermore, the histopathological study confirmed the safety of the formula and its suitability for ocular drug delivery. In sum, all the data indicated that leciplex might be one of the potential ocular delivery systems for hydrophilic drugs.

\section{Disclosure}

The authors report no conflicts of interest in this work.

\section{References}

1. Mehanna MM, Mneimneh AT, Abed El Jalil K. Levofloxacin-loaded naturally occurring monoterpene-based nanoemulgel: a feasible efficient system to circumvent MRSA ocular infections. Drug Dev Ind Pharm. 2020;46 (11):1787-1799. doi:10.1080/03639045.2020.1821048
2. Astley R, Miller FC, Mursalin MH, Coburn PS, Callegan MC. An eye on Staphylococcus aureus toxins: roles in ocular damage and inflammation. Toxins. 2019;11(6):356. doi:10.3390/toxins11060356

3. Shehata M, Fekry AM, Walcarius A. Moxifloxacin hydrochloride electrochemical detection at gold nanoparticles modified screen-printed electrode. Sensors. 2020;20(10):2797. doi:10.3390/s20102797

4. Gade S, Patel KK, Gupta C, et al. An ex vivo evaluation of moxifloxacin nanostructured lipid carrier enriched in situ gel for transcorneal permeation on goat cornea. J Pharm Sci. 2019;108 (9):2905-2916. doi:10.1016/j.xphs.2019.04.005

5. Mustafa S, Devi VK, Pai RS. Effect of PEG and water-soluble chitosan coating on moxifloxacin-loaded PLGA long-circulating nanoparticles. Drug Deliv Transl Res. 2017;7(1):27-36. doi:10. 1007/s13346-016-0326-7

6. Albash R, Al-Mahallawi AM, Hassan M, Alaa-Eldin AA. Development and optimization of terpene-enriched vesicles (Terpesomes) for effective ocular delivery of fenticonazole nitrate: in vitro characterization and in vivo assessment. Int J Nanomedicine. 2021;16:609. doi:10.2147/IJN.S274290

7. Nazzaro F, Fratianni F, Coppola R, Feo VD. Essential oils and antifungal activity. Pharmaceuticals. 2017;10(4):86. doi:10.3390/ ph10040086

8. Hassan DH, Abdelmonem R, Abdellatif MM. Formulation and characterization of carvedilol leciplex for glaucoma treatment: in-vitro, ex-vivo and in-vivo study. Pharmaceutics. 2018;10(4):197. doi:10. 3390/pharmaceutics10040197

9. Salama A, Badran M, Elmowafy M, Soliman GM. Spironolactoneloaded leciplexes as potential topical delivery systems for female acne: in vitro appraisal and ex vivo skin permeability studies. Pharmaceutics. 2020;12(1):25. doi:10.3390/pharmaceutics 12010025

10. El-Nabarawi MA, Shamma RN, Farouk F, Nasralla SM. Dapsoneloaded invasomes as a potential treatment of acne: preparation, characterization, and in vivo skin deposition assay. Aaps Pharmscitech. 2018;19(5):2174-2184. doi:10.1208/s12249-018-1025-0

11. Date AA, Nagarsenker MS, Patere S, et al. Lecithin-based novel cationic nanocarriers (Leciplex) II: improving therapeutic efficacy of quercetin on oral administration. Mol Pharm. 2011;8(3):716-726. doi:10.1021/mp100305h

12. Date AA, Srivastava D, Nagarsenker MS, et al. Lecithin-based novel cationic nanocarriers (LeciPlex) I: fabrication, characterization and evaluation. Nanomedicine. 2011;6(8):1309-1325. doi:10.2217/nnm.11.38

13. Mura P, Maestrelli F, González-Rodríguez ML, Michelacci I, Ghelardini C, Rabasco AM. Development, characterization and in vivo evaluation of benzocaine-loaded liposomes. European $J$ Pharm Biopharm. 2007;67(1):86-95. doi:10.1016/j.ejpb.2007.01.020

14. Xuan T, Zhang JA, Ahmad I. HPLC method for determination of SN-38 content and SN-38 entrapment efficiency in a novel liposome-based formulation, LE-SN38. J Pharm Biomed Anal. 2006;41(2):582-588. doi:10.1016/j.jpba.2005.10.051

15. Abdel-Hafez SM, Hathout RM, Sammour OA. Tracking the transdermal penetration pathways of optimized curcumin-loaded chitosan nanoparticles via confocal laser scanning microscopy. Int $J$ Biol Macromol. 2018;108:753-764. doi:10.1016/j.ijbiomac.2017.10.170

16. Djurdjevic P, Ciric A, Djurdjevic A, Stankov MJ. Optimization of separation and determination of moxifloxacin and its related substances by RP-HPLC. J Pharm Biomed Anal. 2009;50(2):117-126. doi:10.1016/j.jpba.2009.03.029

17. Elsayed I, Sayed S. Tailored nanostructured platforms for boosting transcorneal permeation: box-Behnken statistical optimization, comprehensive in vitro, ex vivo and in vivo characterization. Int J Nanomedicine. 2017;12:7947. doi:10.2147/IJN.S150366

18. Albash R, El-Nabarawi MA, Refai H, Abdelbary AA. Tailoring of PEGylated bilosomes for promoting the transdermal delivery of olmesartan medoxomil: in-vitro characterization, ex-vivo permeation and in-vivo assessment. Int J Nanomedicine. 2019;14:6555. doi:10.21 47/IJN.S213613 
19. Elbaz NM, Khalil IA, Abd-Rabou AA, El-Sherbiny IM. Chitosanbased nano-in-microparticle carriers for enhanced oral delivery and anticancer activity of propolis. Int $J$ Biol Macromol. 2016;92:254-269. doi:10.1016/j.ijbiomac.2016.07.024

20. Albash R, Yousry C, Al-Mahallawi AM, Alaa-Eldin AA. Utilization of PEGylated cerosomes for effective topical delivery of fenticonazole nitrate: in-vitro characterization, statistical optimization, and in-vivo assessment. Drug Deliv. 2021;28(1):1-9. doi:10.1080/ 10717544.2020.1859000

21. Fouda NH, Abdelrehim RT, Hegazy DA, Habib BA. Sustained ocular delivery of Dorzolamide-HCl via proniosomal gel formulation: in-vitro characterization, statistical optimization, and in-vivo pharmacodynamic evaluation in rabbits. Drug Deliv. 2018;25(1):1340-1349. doi:10.1080/10717544.2018.1477861

22. Abdellatif MM, Khalil IA, Elakkad YE, Eliwa HA, Samir TM, AlMokaddem AK. Formulation and characterization of sertaconazole nitrate mucoadhesive liposomes for vaginal candidiasis. Int J Nanomedicine. 2020;15:4079. doi:10.2147/IJN.S250960

23. Fahmy AM, Hassan M, El-Setouhy DA, Tayel SA, Al-Mahallawi AM. Statistical optimization of hyaluronic acid enriched ultradeformable elastosomes for ocular delivery of voriconazole via Box-Behnken design: in vitro characterization and in vivo evaluation. Drug Deliv. 2021;28(1):77-86. doi:10.1080/10717544.2020.1858997

24. Humphries RM, Ambler J, Mitchell SL, et al. CLSI methods development and standardization working group best practices for evaluation of antimicrobial susceptibility tests. J Clin Microbiol. 2018;56 (4). doi:10.1128/JCM.01934-17.

25. Salem MA, El-Shiekh RA, Hashem RA, Hassan M. In vivo antibacterial activity of star anise (Illicium verum Hook.) Extract Using Murine MRSA skin infection model in relation to its metabolite profile. Infect Drug Resist. 2021;14:33. doi:10.2147/IDR.S285940

26. Girgis DO, Sloop GD, Reed JM, O'Callaghan RJ. A new topical model of Staphylococcus corneal infection in the mouse. Invest Ophthalmol Vis Sci. 2003;44(4):1591-1597. doi:10.1167/iovs.02-0656

27. Broekema NM, Larsen IV, Naruzawa ES, et al. A mouse model of multi-drug resistant staphylococcus aureus-induced ocular disease. J Ocular Biol. 2016;4(2).

28. Ezzat MI, Hassan M, Abdelhalim MA, El-Desoky AM, Mohamed SO, Ezzat SM. Immunomodulatory effect of Noni fruit and its isolates: insights into cell-mediated immune response and inhibition of LPS-induced THP-1 macrophage inflammation. Food Funct. 2021;12(7):3170-3179. doi:10.1039/D0FO03402A

29. Ammar HO, Tadros MI, Salama NM, Ghoneim AM. Ethosome-derived invasomes as a potential transdermal delivery system for vardenafil hydrochloride: development, optimization and application of physiologically based pharmacokinetic modeling in adults and geriatrics. Int J Nanomedicine. 2020;15:5671. doi:10.2147/IJN.S261764

30. Mura S, Manconi M, Sinico C, Valenti D, Fadda AM. Penetration enhancer-containing vesicles (PEVs) as carriers for cutaneous delivery of minoxidil. Int J Pharm. 2009;380(1-2):72-79. doi:10.1016/j. ijpharm.2009.06.040

31. Vidya K, Lakshmi P. Cytotoxic effect of transdermal invasomal anastrozole gel on MCF-7 breast cancer cell line. J Appl Pharm Sci. 2019;9(03):050-058.

32. Le-deygen IM, Skuredina AA, Safronova AS, et al. Moxifloxacin interacts with lipid bilayer, causing dramatic changes in its structure and phase transitions. Chem Phys Lipids. 2020;228:104891. doi:10.1016/j.chemphyslip.2020.104891

33. Carbone C, Tomasello B, Ruozi B, Renis M, Puglisi G. Preparation and optimization of PIT solid lipid nanoparticles via statistical factorial design. Eur J Med Chem. 2012;49:110-117. doi:10.1016/j.ejmech.2012.01.001

34. Al-Mahallawi AM, Khowessah OM, Shoukri RA. Nanotransfersomal ciprofloxacin loaded vesicles for non-invasive trans-tympanic ototopical delivery: in-vitro optimization, ex-vivo permeation studies, and in-vivo assessment. Int J Pharm. 2014;472 (1-2):304-314. doi:10.1016/j.jpharm.2014.06.041
35. Tawfik MA, Tadros MI, Mohamed MI, El-Helaly SN. Low-frequency versus high-frequency ultrasound-mediated transdermal delivery of agomelatine-loaded invasomes: development, optimization and in-vivo pharmacokinetic assessment. Int $J$ Nanomedicine. 2020;15:8893. doi:10.2147/IJN.S283911

36. Badawi NM, Teaima MH, El-Say KM, Attia DA, El-Nabarawi MA, Elmazar MM. Pomegranate extract-loaded solid lipid nanoparticles: design, optimization, and in vitro cytotoxicity study. Int J Nanomedicine. 2018;13:1313. doi:10.2147/IJN.S154033

37. Ammar HO, Mohamed MI, Tadros MI, Fouly AA. Transdermal delivery of ondansetron hydrochloride via bilosomal systems: in vitro, ex vivo, and in vivo characterization studies. AAPS PharmSciTech. 2018;19 (5):2276-2287. doi:10.1208/s12249-018-1019-y

38. Rabinovich-Guilatt L, Couvreur P, Lambert G, Dubernet C. Cationic vectors in ocular drug delivery. J Drug Target. 2004;12(910):623-633. doi:10.1080/10611860400015910

39. Lallemand F, Daull P, Benita S, Buggage R, Garrigue J-S. Successfully improving ocular drug delivery using the cationic nanoemulsion, novasorb. $J$ Drug Deliv. 2012;2012:604204. doi:10.1155/2012/604204

40. Mudgil M, Pawar PK. Preparation and in vitro/ex vivo evaluation of moxifloxacin-loaded PLGA nanosuspensions for ophthalmic application. Sci Pharm. 2013;81(2):591-606. doi:10.3797/scipharm.1204-16

41. Salem HF, Kharshoum RM, Abou-Taleb HA, AbouTaleb HA, AbouElhassan KM. Progesterone-loaded nanosized transethosomes for vaginal permeation enhancement: formulation, statistical optimization, and clinical evaluation in anovulatory polycystic ovary syndrome. J Liposome Res. 2019;29(2):183-194. doi:10.1080/ 08982104.2018 .1524483

42. Takeuchi H, Thongborisute J, Matsui Y, Sugihara H, Yamamoto H, Kawashima Y. Novel mucoadhesion tests for polymers and polymer-coated particles to design optimal mucoadhesive drug delivery systems. Adv Drug Deliv Rev. 2005;57(11):1583-1594. doi:10.1016/j.addr.2005.07.008

43. Fahmy AM, Hassan M, El-Setouhy DA, Tayel SA, Al-Mahallawi AM. Voriconazole ternary micellar systems for the treatment of ocular mycosis: statistical optimization and in vivo evaluation. J Pharm Sci. 2020;110(5);2130-2138.

44. Chojnacki M, Philbrick A, Wucher B, et al. Development of a broad-spectrum antimicrobial combination for the treatment of Staphylococcus aureus and Pseudomonas aeruginosa corneal infections. Antimicrob Agents Chemother. 2019;63(1).

45. Li Y, Zhen J, Tian Q, et al. One step synthesis of positively charged gold nanoclusters as effective antimicrobial nanoagents against multidrug-resistant bacteria and biofilms. J Colloid Interface Sci. 2020;569:235-243. doi:10.1016/j.jcis.2020.02.084

46. Ban J, Zhang Y, Huang X, et al. Corneal permeation properties of a charged lipid nanoparticle carrier containing dexamethasone. Int J Nanomedicine. 2017;12:1329. doi:10.2147/IJN.S126199

47. Trewyn BG, Whitman CM, Lin VS-Y. Morphological control of room-temperature ionic liquid templated mesoporous silica nanoparticles for controlled release of antibacterial agents. Nano Lett. 2004;4 (11):2139-2143. doi:10.1021/n1048774r

48. Lorenzo-Veiga B, Diaz-Rodriguez P, Alvarez-Lorenzo C, Loftsson T, Sigurdsson HH. In vitro and ex vivo evaluation of Nepafenac-based cyclodextrin microparticles for treatment of eye inflammation. Nanomaterials. 2020;10(4):709. doi:10.3390/nano10040709 


\section{Publish your work in this journal}

The International Journal of Nanomedicine is an international, peerreviewed journal focusing on the application of nanotechnology in diagnostics, therapeutics, and drug delivery systems throughout the biomedical field. This journal is indexed on PubMed Central, MedLine, CAS, SciSearch ${ }^{\mathbb{R}}$, Current Contents ${ }^{\mathbb{B}} /$ Clinical Medicine,

Journal Citation Reports/Science Edition, EMBase, Scopus and the Elsevier Bibliographic databases. The manuscript management system is completely online and includes a very quick and fair peer-review system, which is all easy to use. Visit http://www.dovepress.com/ testimonials.php to read real quotes from published authors.

Submit your manuscript here: https://www.dovepress.com/international-journal-of-nanomedicine-journal 